\title{
Rhizobial exopolysaccharides: genetic control and symbiotic functions
}

\author{
Anna Skorupska*, Monika Janczarek, Małgorzata Marczak, Andrzej Mazur \\ and Jarosław Król
}

Address: Department of General Microbiology, University of M. Curie-Skłodowska, Akademicka 19 st., 20-033 Lublin, Poland

Email: Anna Skorupska* - genet@biotop.umcs.lublin.pl; Monika Janczarek - mjanczar@biotop.umcs.lublin.pl; Małgorzata Marczak - mmarczak@hektor.umcs.lublin.pl; Andrzej Mazur - mazur@hektor.umcs.lublin.pl;

Jarosław Król - jekrol@ @ektor.umcs.lublin.pl

* Corresponding author

Published: 16 February 2006

Microbial Cell Factories 2006, 5:7 doi:10.1 186/1475-2859-5-7
Received: 21 December 2005

Accepted: 16 February 2006

This article is available from: http://www.microbialcellfactories.com/content/5///7

(c) 2006 Skorupska et al; licensee BioMed Central Ltd.

This is an Open Access article distributed under the terms of the Creative Commons Attribution License (http://creativecommons.org/licenses/by/2.0), which permits unrestricted use, distribution, and reproduction in any medium, provided the original work is properly cited.

\begin{abstract}
Specific complex interactions between soil bacteria belonging to Rhizobium, Sinorhizobium, Mesorhizobium, Phylorhizobium, Bradyrhizobium and Azorhizobium commonly known as rhizobia, and their host leguminous plants result in development of root nodules. Nodules are new organs that consist mainly of plant cells infected with bacteroids that provide the host plant with fixed nitrogen. Proper nodule development requires the synthesis and perception of signal molecules such as lipochitooligosaccharides, called Nod factors that are important for induction of nodule development. Bacterial surface polysaccharides are also crucial for establishment of successful symbiosis with legumes. Sugar polymers of rhizobia are composed of a number of different polysaccharides, such as lipopolysaccharides (LPS), capsular polysaccharides (CPS or K-antigens), neutral $\beta$-I, 2-glucans and acidic extracellular polysaccharides (EPS). Despite extensive research, the molecular function of the surface polysaccharides in symbiosis remains unclear.

This review focuses on exopolysaccharides that are especially important for the invasion that leads to formation of indetermined (with persistent meristem) type of nodules on legumes such as clover, vetch, peas or alfalfa. The significance of EPS synthesis in symbiotic interactions of Rhizobium leguminosarum with clover is especially noticed. Accumulating data suggest that exopolysaccharides may be involved in invasion and nodule development, bacterial release from infection threads, bacteroid development, suppression of plant defense response and protection against plant antimicrobial compounds. Rhizobial exopolysaccharides are species-specific heteropolysaccharide polymers composed of common sugars that are substituted with non-carbohydrate residues. Synthesis of repeating units of exopolysaccharide, their modification, polymerization and export to the cell surface is controlled by clusters of genes, named exol exs, exp or pss that are localized on rhizobial megaplasmids or chromosome. The function of these genes was identified by isolation and characterization of several mutants disabled in exopolysaccharide synthesis. The effect of exopolysaccharide deficiency on nodule development has been extensively studied. Production of exopolysaccharides is influenced by a complex network of environmental factors such as phosphate, nitrogen or sulphur. There is a strong suggestion that production of a variety of symbiotically active polysaccharides may allow rhizobial strains to adapt to changing environmental conditions and interact efficiently with legumes.
\end{abstract}




\section{Review \\ Introduction}

Under nitrogen-limiting conditions, Gram-negative soil bacteria belonging to genera Rhizobium, Sinorhizobium, Mesorhizobium, Phylorhizobium, Bradyrhizobium and Azorhizobium, commonly named rhizobia, have the ability to establish root symbiosis with certain legumes. Upon stimulation by flavonoids exuded from legume roots into soil, rhizobia synthesize signaling molecules that are responsible for nodule formation [1-3]. These signaling molecules, named Nod factors, have been identified as lipochito oligosaccharides (LCOs) having diverse chemical substitutions. Nod factors are sufficient for initiation of root hair deformations $\left(\mathrm{Had}^{+}, \mathrm{Hac}^{+}\right)$, infection thread formation $\left(\mathrm{Thr}^{+}\right)$and activation of cortical cells division [2]. Rhizobia colonize plant root hairs and infection threads develop within them. Inside the infection threads rhizobia multiply and invade developing nodules. Nodules formed on plant hosts fall into two different types: indeterminate and determinate. Temperate legumes such as clover, pea or alfalfa form indeterminate nodules, which are cylindrical in shape, with a persistent apical meristem responsible for the nodule growth. Tropical legumes such as soybean or common bean form determinate nodules, which are spherical with nonpersistent meristem. In both cases, the nodule is infected through infection thread, bacteria are released into cortical cells and surrounded by the peribacteroid membranes differentiate into bacteroids. Bacteroids synthesize the nitrogenase complex and other proteins that allow them to fix nitrogen and convert it into ammonia. In turn, plants supply bacteria with carbohydrates as a source of carbon and energy. Each step of establishment of symbiosis is tightly controlled through a complex network of signaling cascades [2-4].

Among a number of known rhizobial genes required for initiation and elongation of infection threads, the genes responsible for production of different types of cell-surface polysaccharides play a major role. Surface polysaccharides that form an adherent cohesive layer on the cell surface are designated capsular polysaccharides (CPS), whereas the term exopolysaccharides (EPS) is used for polysaccharides with little or no cell association $[5,6]$. Cyclic $\beta$ - $(1,2)$-glucans are generally concentrated in the periplasmic space of rhizobia, where they play an important role in osmotic adaptation of bacteria $[7,8]$. Lipopolysaccharides (LPS) are anchored in the outer membrane and are constituted by lipid A, a core oligosaccharide and an $\mathrm{O}$-antigen polysaccharide. Despite extensive research, the precise role of the surface polysaccharides in symbiosis remains unclear.

The significance of several types of surface polysaccharide has been studied extensively in model symbiosis of Sinor- hizobium meliloti with alfalfa and was recently reviewed by Becker et al. [9] and Fraysse et al. [10]. This review focuses on the genetic control of exopolysaccharide synthesis, regulation and biological functions in symbiotic interactions with host legumes. Importance of EPS production in Rhizobium leguminosarum symbiotic interaction with clover is especially noticed.

\section{Structural features of rhizobial exopolysaccharides}

Rhizobial exopolysaccharides are species- or strain-specific heteropolysaccharides (they are composed of different kinds of monosaccharides) consisting of repeating units. They are secreted into the environment (EPS) or retained at the bacterial surface as a capsular polysaccharide (CPS). A large diversity in EPS chemical structures can be found among rhizobia, concerning sugar composition and their linkage in the single subunit, repeating unit size and degree of polymerization as well as non-carbohydrate decoration [5,11-13].

One of the best known rhizobial EPS is succinoglycan (EPS I) produced by several S. meliloti strains [14]. It is composed of octasaccharide repeating units containing one galactose and seven glucose residues (in molar ratio $1: 7)$, joined by $\beta-1,3, \beta-1,4$ and $\beta-1,6$ glycosidic linkages (Fig. 1A). Single repeating unit is decorated by acetyl, pyruvyl and succinyl groups (Fig. 1A). S. meliloti has also the ability to produce another distinct exopolysaccharide designated galactoglucan or EPS II $[15,16]$. EPS II is synthesized only under phosphate starvation [17] or when mutation in one of the regulatory genes, either $m u c R$ $[18,19]$ or $\exp R[20,21]$ occurs. It differs significantly in structure from EPS I. It is a polymer of disaccharide repeating unit composed of an acetylated glucose and one pyruvylated galactose coupled by $\alpha-1,3$ and $\beta-1,3$ glycosidic bonds [15] (Fig. 1B). Both EPS I and II are secreted in two major fractions reflecting different degrees of subunit polymerization: HMW - High Molecular Weight, consisting of hundreds to thousands of repeating units (polymers of $10^{6}-10^{7} \mathrm{Da}$ ) and LMW - Low Molecular Weight that represent monomers, dimers and trimers in a case of EPS I and oligomers (15-20) in a case of EPS II [22-24].

EPS I and EPS II produced by the wild-type S. meliloti strain 1021 are symbiotically active exopolysaccharides. $S$. meliloti laboratory strain Rm41 produces form of capsular polysaccharide, termed $\mathrm{K}$ antigen that is symbiotically active when EPS is absent. K antigens of Sinorhizobium are structurally analogous to group II $\mathrm{K}$ antigens (capsular polysaccharides) found in E. coli and can substitute for succinoglycan and galactoglucan in the nodule invasion step of symbiosis, although EPS I, EPS II and K antigen are structurally diverse polysaccharides [25-27]. Sinorhizobium $\mathrm{K}$ antigens conform to the consensus structure: Hex$\mathrm{Kdx}$, where Hex is any hexose and Kdx is any 1-carboxy-2- 
A)

S. meliloti EPS I

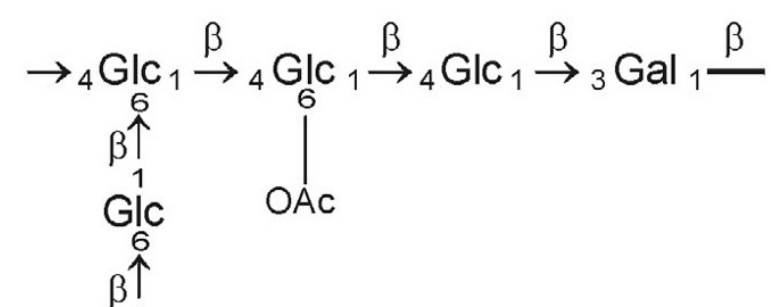

B)

S. meliloti EPS II

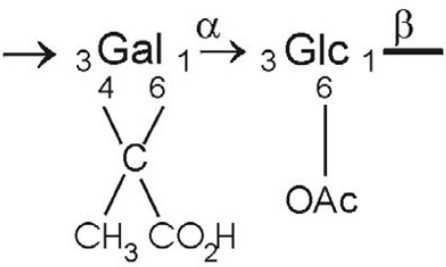

C)

R. leguminosarum bv. trifolii

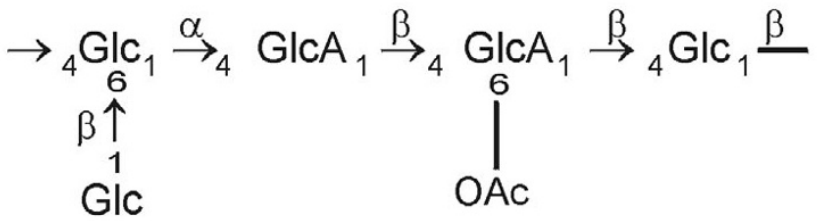

${ }_{6}^{4} \mathrm{GlC}_{6}>\mathrm{C}=\underset{\mathrm{CH}_{3}}{\mathrm{CO}_{2} \mathrm{H}}$

1

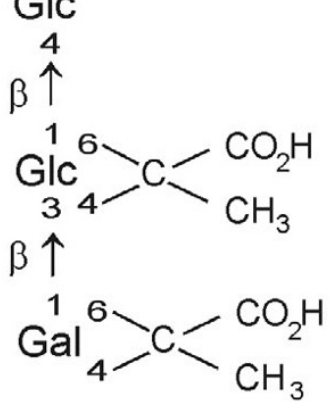

D)

R. leguminosarum bv. trifolii $4 \mathrm{~S}$

$\beta-\mathrm{Glc}_{6}-(1 \rightarrow 3)-\beta-\mathrm{Glc}-(1 \rightarrow 4)-\beta-\mathrm{Glc}$

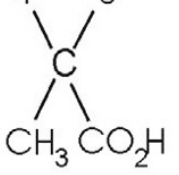

E)

R. leguminosarum bv. viciae 248

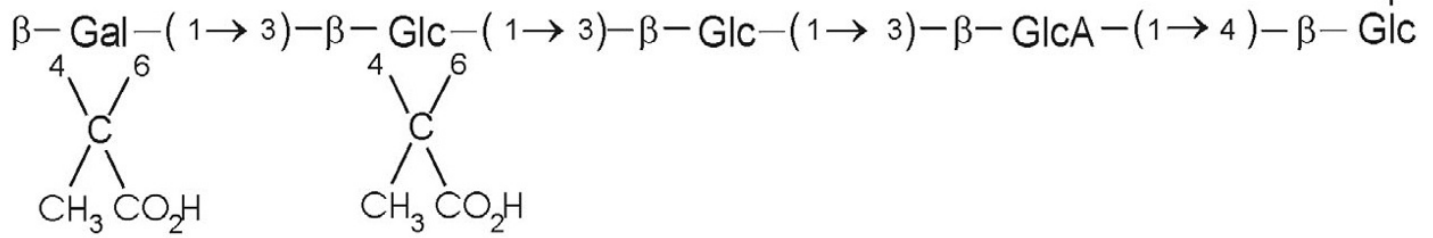

Figure I

The chemical structures of the rhizobial exopolysaccharide (EPS) repeating units. A)-B) S. meliloti, C) Rhizobium leguminosarum bv. trifolii, D) R. leguminosarum bv. trifolii 4S, E) R. leguminosarum bv. viciae 248. Abbreviations: Glc, glucose, GlcA, glucuronic acid, Gal, galactose, Succ, succinate, and Ac, acetyl. 
keto-3-deoxy sugar, e.g. 3-deoxy-D-manno-2-octulosonic acid (Kdo) or sialic acid. K antigens of each strain are distinguished by their glycosyl composition, anomeric configuration, acetylation pattern and molecular weight distribution [26,27].

Rhizobium leguminosarum strains, although included into different biovars (i.e. trifolii and viciae) and nodulating different plant hosts, have the same conserved octasaccharide repeating unit of EPS, composed of glucose, glucuronic acid and galactose in the molar ratio of $5: 2: 1$ $[28,29]$ (Fig. 1C). However, certain strains of R. leguminosarum secrete EPS, the repeating unit of which differs in sugar content and the length of the side chain. In R. trifolii $4 \mathrm{~S}$, the EPS subunit composed of seven sugars, lacking terminal galactose from the side chain, was described [30] (Fig. 1D). On the other hand, in Rhizobium leguminosarum bv. viciae 248 the repeating unit with additional glucuronic acid in the side chain was reported [31] (Fig. 1E). Nevertheless, all the EPSs mentioned above are similar by means of possessing identical backbones and the same $\beta$ 1,6 linked glucosyl residue starting the side chain (Fig. $1 \mathrm{C}-\mathrm{E})$. The pattern of non-sugar decoration with acetyl, pyruvyl and hydroxybutanoyl residues was found to be different for several R. leguminosarum strains [29,32] (Fig. $1 \mathrm{C}-\mathrm{E})$.

In R. leguminosarum, acidic CPS has similar or even identical structure to the EPS [33,34]. However, distribution of noncarbohydrate residues, such as O-acetate, pyruvate, and 3-hydroxybutyrate, distinguishes CPS from secreted acidic EPS [29,32]. Defects in the synthesis of EPS and/or capsular polysaccharides have a pleiotropic effect resulting in significant increase in the synthesis and secretion of cyclic $\beta$-1, 2-glucans [8,34].

In $R$. leguminosarum, K-antigen-like polysaccharide has not been reported. Similarly to $S$. meliloti, R. leguminosarum strains can produce EPS species differing in molecular weight - HMW and LMW respectively $[35,36]$.

\section{Genetic control of EPS synthesis}

Genes directing the biosynthesis of exopolysaccharides (exo/exs or pss genes) form large clusters located either on the chromosome or on the megaplasmids [37,38]. Among the proteins encoded within such regions there are: the transferases responsible for the assembly of the EPS repeating unit, the enzymes involved in the biosynthesis of nucleotide sugar precursors, the enzymes involved in modifying EPS with non-sugar decorations, and proteins engaged in the polymerization and export of the growing EPS chain onto the cell surface [39-42].

Exopolysaccharide biosynthesis represents a multi-step process and depends on the activity of a protein complex localized both in the inner (IM) and the outer membrane (OM). Precursors, nucleotide diphospho-sugars, are sequentially transferred to growing polysaccharide chain attached to an acceptor due to the activity of specific glycosyltransferases. Undecaprenol diphosphate was identified as a sugar acceptor in the case of most heteropolysaccharides [5]. The repeating unit is formed at the inner leaflet of the cytoplasmic membrane. The blockwise polymerization of individual repeating units takes place at the periplasmic face of the inner membrane after they have been flipped across the IM in a process involving Wzx-like translocase or "flippase" protein. Polymerization is thought to be coupled to export of the growing polymer to the cell surface and engages Wzy-like polymerase [42-44] and Wzc-like inner membrane-periplasmic auxiliary protein (MPA) with an ABC module $[42,45,46]$. The latter protein is proposed to control the chain length of the growing heteropolymer. Completion of the translocation process depends on the outer membrane auxiliary protein (OMA), forming a channel in the outer membrane thus facilitating the growing polysaccharide to reach the cell surface [45]. It was proposed that effective translocation of EPS is the result of physical association of the proteins localized in both membranes [36,45].

EPS synthesis and regulation were extensively studied in the case of succinoglycan (EPS I) produced by S. meliloti. The data concerning synthesis of acidic exopolysaccharide in R. leguminosarum are more fragmentary.

\section{Sinorhizobium meliloti}

S. meliloti possesses a multipartite genome. It contains three replicons: a chromosome $(3.65 \mathrm{Mb})$ and two megaplasmids: pSymA (1.35 Mb) and pSymB (1.68 Mb). The exo/exs gene cluster, directing the biosynthesis of succinoglycan (EPS I) is located on a megaplasmid 2 (pSymB) [47]. After the completion of S. meliloti genome sequencing project, it appeared that only 2 out of 11 regions engaged in polysaccharides biosynthesis were previously recognized on pSymB [37,39,40,48,49]. 14\% (223 kpz) of this plasmid comprise the genes connected with the biosynthesis of polysaccharides [38].

Although all EPS I biosynthetic genes are clustered on pSymB, there are some other genes important for succinoglycan biosynthesis and its regulation $($ exoC, exoR, exoS, mucR, exoD) that were mapped on the chromosome $[18,19,50-54]$. The exo/exs genes are organized in several operons $[48,49,55-57]$.

In the biosynthesis of succinoglycan, nucleotide sugar precursors are firstly synthesized. exoC gene encodes a phosphoglucomutase that catalyze transformation of glucose6-phosphate into glucose-1-phosphate [58]. exoB encodes for the UDP-glucose-4-epimerase that converts UDP-glu- 


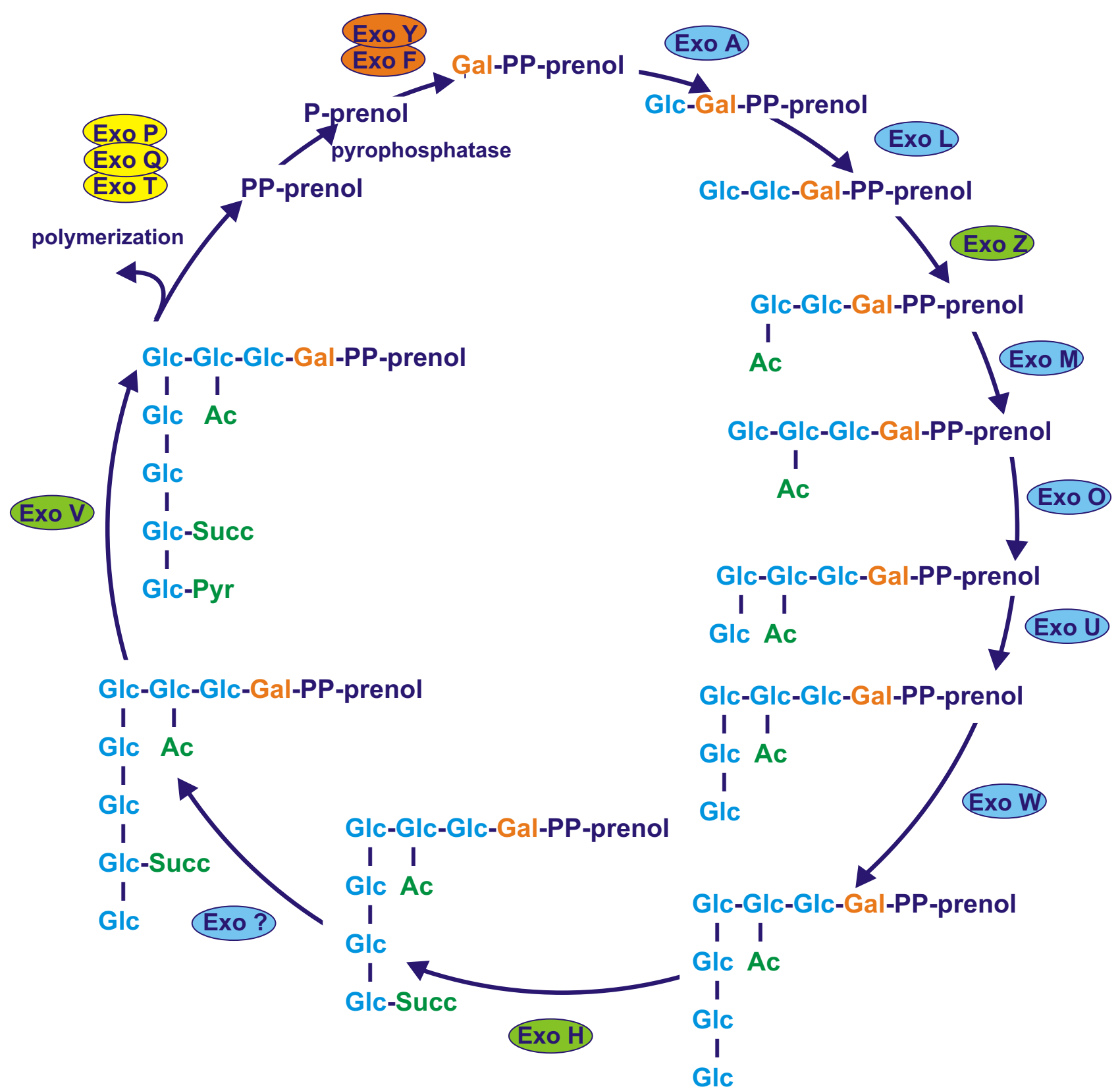

Figure 2

Pathway for the assembly of the repeating unit of EPS I in S. meliloti based on [5, 39, 40, 48, 49, 59]. The synthesis involves three groups of proteins: a) the proteins involved in the biosynthesis of nucleotide sugar precursors (not shown); b) the sugar transferases, engaged in the transfer of precursors onto the lipid carrier (proteins shown in orange and blue); c) modifying enzymes, decorating the unit with non-sugar moieties (green); d) proteins involved in EPS assembly and export (yellow). Abbreviations used: Glc, glucose; Gal, galactose; Ac, acetate; Pyr, pyruvate; Succ, succinate.

cose to UDP-galactose [55]. exoB and exoC mutations cause the lack of EPS I production but also affect the synthesis of other polymers - EPS II, LPS and $\beta$-glucans. A protein encoded by exoN gene displays UDP-glucose pirophosphorylase activity. Mutation in exoN results in a decrease in EPS I production $[40,48]$. 


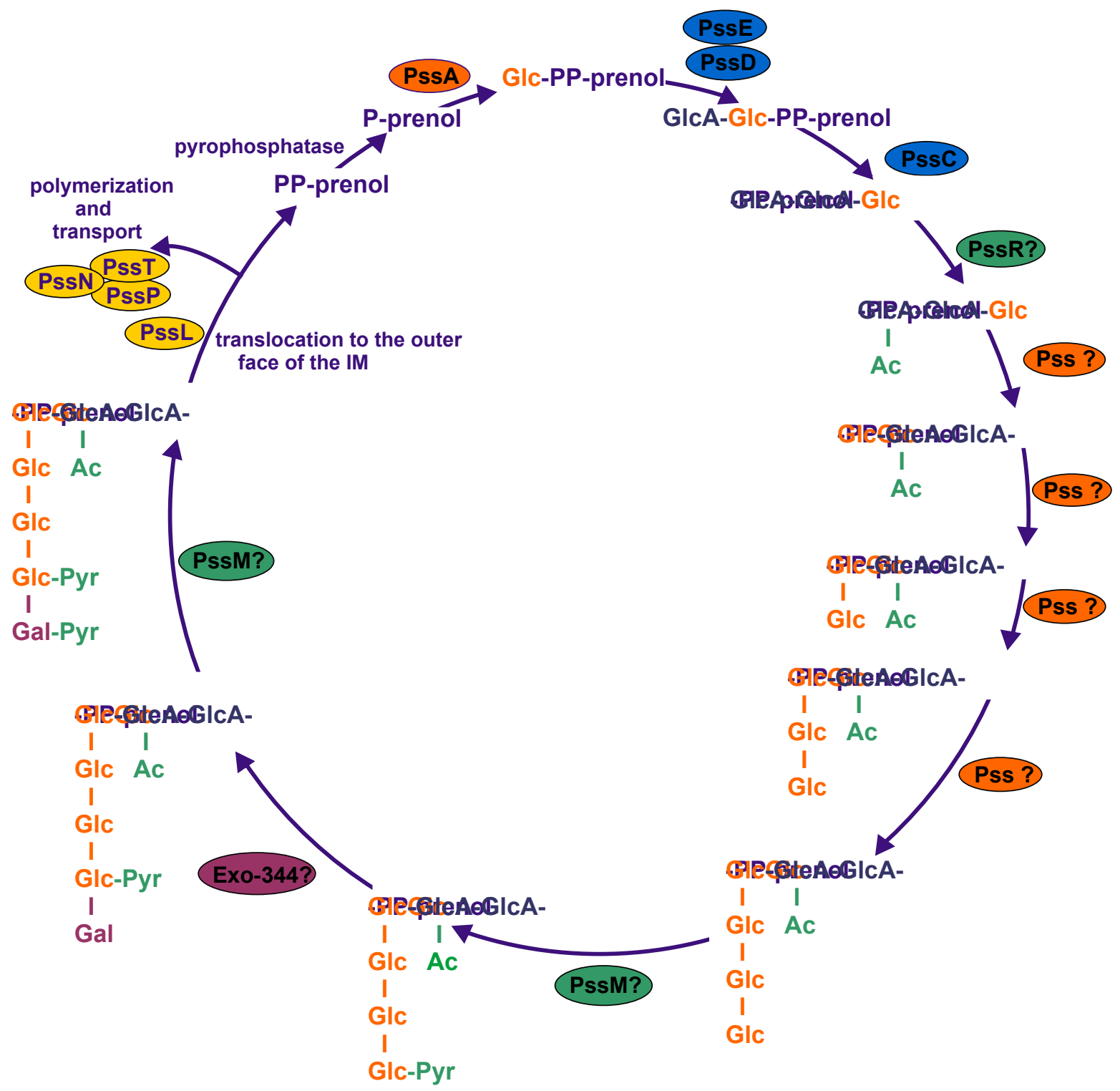

Figure 3

Schematic representation of EPS repeating unit biosynthesis and polymerization in $R$. leguminosarum. Based on 8, 36, 79-82, 8487, 89-9I. Question marks indicate putative, based on the results of homology searches, function of PssR, PssM and other Pss/ Exo proteins. Colour marks of the proteins respond to those in Fig. 2. Abbreviations used: Glc, glucose; GlcA, glucuronic acid; Gal, galactose; Ac, acetate; Pyr, pyruvate; IM, inner membrane.

Assembly of the repeating unit is initiated by ExoY galactosyltransferase [59,60] [Fig. 2]. exoY mutant, which does not produce succinoglycan, is symbiotically defective because it cannot initiate the formation of infection threads [61]. exoF gene encodes a protein that is needed for addition of galactose to the lipid carrier [60]. The subsequent addition of glucose residues is carried out by a complex of glucosyltransferases encoded by exoA, exoL,
exoM, exoO, exoU and exoW genes [39,48,49,60]. Mutations in exoF, exoA, exoL and exoM genes were shown to completely abolish succinoglycan production and resulted in mutants that formed Fix nodules [62-65]. exoO mutation resulted in the strain producing large amounts of insoluble carbohydrate material, consisting of polymerized four-sugar subunits [39]. exoU and exoW 


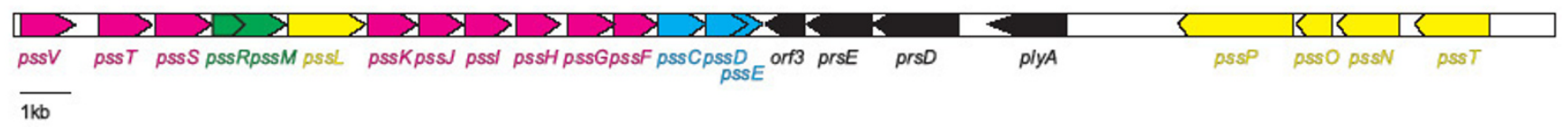

\section{Figure 4}

Genetic organization of the pss gene clusters of $R$. leguminosarum based on GenBank accesions: $\underline{A F 028810}, \underline{X 98117}, \underline{Y} 12758$, $\underline{X 9850}, \underline{A F 040104}, \underline{A Y 237541}, \underline{A F 014054}, \underline{X 98117}, \underline{A F 067140}$ and AF402596. Colour marks of the pss genes respond to colours of the proteins shown in Fig. 3

mutants produced no detectable amounts of EPS I and were not able to infect alfalfa nodules [49].

The growing EPS I repeating unit is modified by addition of non-sugar residues. exoH gene of $S$. meliloti encodes for the transmembrane protein with succinyltransferase activity. exoH mutants produced symbiotically nonfunctional high-molecular-weight EPS I that lacked the succinyl modification. The mutant induced formation of ineffective nodules that did not contain intracellular bacteria or bacteroids. Root hair curling was also significantly delayed and infection threads aborted in the nodule cortex $[61,66]$. A transferase encoded by exoZ gene is involved in addition of acetyl residues. An exoZ mutant, which produces succinoglycan without the acetyl modification, forms nitrogen-fixing nodules on plants, but it exhibits a reduced efficiency in the initiation and elongation of infection threads $[41,55,61]$. exoV mutants are defective in EPS I synthesis; they accumulate units lacking pyruvyl residues. This indicates that this modification is crucial for the polymerization and secretion of succinoglycan $[40,49,60]$.

Polymerization of the succinoglycan repeating units and secretion of the polymer depend on the proteins encoded by the exoPQT genes [40]. ExoP of S. meliloti is an autophosphorylating protein tyrosine kinase and was proposed to have a critical role in EPS biosynthesis: enzymatic, as it catalyzes the formation of dimers of octasaccharide units of EPS I, and structural, by forming a complex with ExoQ and ExoT proteins which participate in the secretion of succinoglycan [67]. It was evidenced that ExoQ protein is indispensable for high-molecularweight (HMW) EPS I biosynthesis, while ExoT is responsible for producing low-molecular-weight (LMW) EPS, i.e. trimers and tetramers of the basic subunit $[23,41]$. The mutants in exoPQT did not synthesize succinoglycan, but were capable of accumulating octasaccharides acylated, succinylated and pyruvylated to various extents [64].
ExsA protein of $S$. meliloti is homologues to ABC transporters and is important for the transport of HMW EPS I. exs A mutant secreted both LMW and HMW forms of succinoglycan in almost equal amounts [57].

Symbiotically active, low-molecular-weight EPS I is produced in $S$. meliloti by a specific biosynthetic pathway but it can also result from a cleavage of HMW succinoglycan by endoglycanases: ExoK ( $\beta$-1, 3-1, 4-glucanase) and ExsH (succinoglycan depolymerase), the latter of which is secreted by PrsDE secretion system [68]. It was shown that acetyl and succinyl modifications of EPS I influence the susceptibility of the polysaccharide to cleavage by these glycanases [69].

The second exopolysaccharide produced by $S$. meliloti, the biosynthesis of which is directed by exp genes, is galactoglucan (EPS II). $23 \mathrm{~kb}$ exp gene cluster is localized on pSymB plasmid and is separated from exo/exs cluster by about $200 \mathrm{~kb}$. Biosynthesis of nucleotide diphosphosugar precursors depends on the activity of ExpA7, ExpA8, ExpA9 and ExpA10 proteins, which are involved in formation of dTDP-rhamnose. The intermediate in this synthesis dTDP-glucose, serves as the donor of glucose in EPS II synthesis (in contrast to UDP-glucose which is a precursor of glucose in EPS I synthesis). Other genes in the cluster were shown to be involved in polymerization of sugars $(\beta$ glucosyltransferases ExpA2 and ExpE2, galactosyltransferases ExpA3, ExpC, ExpE4 and ExpE7), the export of EPS II and the regulation of exp gene expression [70]. The expE1 gene encodes the secreted protein that binds calcium ions. It shows some similarity to NodO protein of $R$. leguminosarum bv. viciae [71]. ExpD1 (ABC transporter) and ExpD2 (MFP - membrane fusion protein) are required for ExpE1 secretion and are homologous to PrtD/PrtE secretion system of Erwinia chrysanthemi. expD1 and $\operatorname{expD2}$ mutants were shown to be blocked in EPS II synthesis and secretion $[70,72]$. 


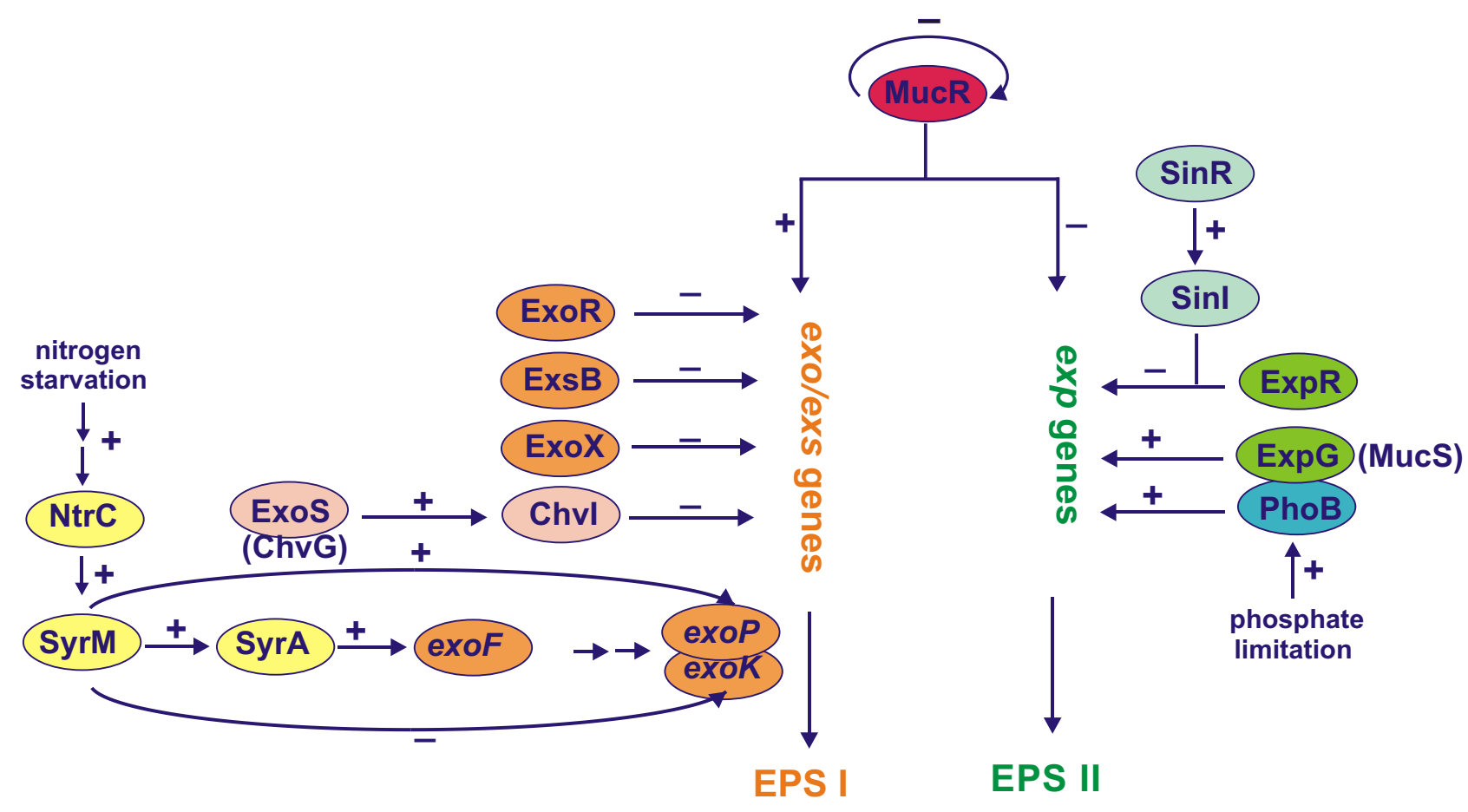

Figure 5

Model of the regulation of succinoglycan (EPS I) and galactoglucan (EPS II) production in S. meliloti based on [3, 5, I03, I05, 106].

\section{Rhizobium leguminosarum}

Rhizobium leguminosarum comprises two biovars: viciae and trifolii that differ in their host-specificity, and is a close relative of Rhizobium etli (formerly the third biovar - phaseoli). The genome of $R$. leguminosarum consists of the chromosome and 1-10 megaplasmids [73,74]. Completion of the R. leguminosarum bv. viciae genome sequencing project revealed that its genome consists of a circular chromosome of $5 \mathrm{Mb}$, and six plasmids: pRL12 (870 kb), pRL11 (684 kb), pRL10 (488 kb), pRL9 (352 kb), and pRL8 (147 kb) [75]. Rhizobium leguminosarum bv. trifolii TA1 genome consists of $7.3 \mathrm{Mb}$ and is separated into 5 replicons: the chromosome and 4 plasmids: pRTA1d ( 800 $\mathrm{kb})$, pRTA1c (650 kb), pRTA1b (600 kb) and pRTA1a (500 kb) [76].

EPS biosynthetic clusters carry genes engaged in the biosynthesis of nucleotide precursors. exoB gene of R. leguminosarum bv. trifolii encodes a protein showing $80 \%$ identity to the UDP-glucose 4-epimerase of S. meliloti [55]. ExoB is the enzyme involved in the biosynthesis of an UDP-galactose, which is the donor of galactose residues for different heteropolysaccharides in rhizobia. Disruption of the gene led to synthesis of an exopolysaccharide lacking galactose and the mutant was almost unable to invade plant cells and induced abnormal root nodules [77].

exo5 mutant of $R$. leguminosarum has a pleiotropic phenotype and is affected in glucuronic acid (GlcA) and galacturonic acid (GalA)-containing polysaccharides, such as EPS, CPS and LPS [34]. Exo5 protein has a functional and structural homology to RkpK of S. meliloti - an UDP-glucose dehydrogenase, which is responsible for the oxidation of UDP-glucose to UDP-glucuronic acid [78].

The biosynthesis of EPS in R. leguminosarum is initiated by the transfer of an UDP-glucose to the lipid carrier attached to the cytoplasmic membrane [Fig. 3]. The enzyme involved in this process, glucosyl-IP-transferase, is encoded by conserved pssA gene, found in R. leguminosarum bv. trifolii, viciae and R. etli [79-82]. Mutations in pssA gene in $R$. leguminosarum resulted in non-mucoid phenotype and induction of non-nitrogen-fixing nodules on pea, vetch and clover $[79,83,84]$.

In the subsequent step of unit synthesis glucuronosyl-( $\beta$ $1,4)$-glucosyl transferase catalyses the addition of a glucuronic acid residue. $p s s D$ and $p s s E$ genes encoding this activity were identified in both $R$. leguminosarum biovars $[80,85]$ and the common action of both proteins as glu- 
curonosyl transferase was proposed $[86,87]$. pssD mutant revealed non-mucoid phenotype and induced non-nitrogen-fixing nodules on clover, hardly infected with bacteria $[80,85]$.

The addition of the second glucuronic acid residue depends on the activity of $p s s C$ gene product, a glucuronosyl- $\beta$-1, 4-glucuronosyltransferase [80,84-86]. $p s s C$ mutant still synthesized EPS, although less than a half an amount of the parental strain, and induced nodules infected with bacteria able to fix nitrogen on clover [80] or failed to nodulate vetch [84].

Guerreiro et al. [87] used proteomic approach to study protein-expression profiles in response to mutations in $p s s A$ and $p s s D / E$ genes. Mutations, besides abolishing the capacity to synthesize EPS, had pleiotropic effect and appeared as the change in the protein synthesis level [87]. The pss $A$ mutation caused differences in the level of 22 and 23 proteins in $R$. leguminosarum bv. viciae and R. leguminosarum bv. trifolii, respectively. Besides being a glucosyltransferase, $p s s A$ gene product may probably serve other functions, by affecting the expression of a number of other genes [87]. Mutations in $p s s D$ and $p s s E$ led not only to loss of EPS synthesis, but also to an alteration in synthesis of 9 out of 22 proteins affected in pssA mutant. Identical differences in the protein synthesis in both $p s s D$ and $p s s E$ mutants support the hypothesis of their common action as glucuronosyltransferase [87].

Subsequent steps of acidic EPS synthesis were poorly studied, although the genes $p s s F, p s s G, p s s H, p s s I, p s s J$ and $p s s S$ encoding putative glycosyltransferases and $p s s R$ and $p s s M$ genes predicted to encode EPS modifying enzymes were identified in R. leguminosarum bv. viciae [84]. Breedveld et al. identified in R. leguminosarum bv. viciae a gene encoding a protein with significant similarity to a family of glycosyltransferases, involved in the transfer of galactosyl residues during the polysaccharide unit assembly. The mutant strain exo-344::Tn5 synthesized repeating units lacking terminal galactose and the substituents attached to it, comparable to those produced by the exoB mutant [8].

$p s s T, p s s N$ and $p s s P$ genes encode proteins that form secretion system involved in the assembly and export of EPS in R. leguminosarum bv. trifolii TA1. PssT is an integral inner membrane protein similar in its topology to Wzy polymerase of $\mathrm{O}$-antigen repeating units of LPS and group 1 and $4 \mathrm{~K}$-antigens repeat units $[36,42,46]$. pssT mutant overproduced EPS with degree of polymerization slightly increased when compared to the wild type strain [36]. PssP is similar to membrane-periplasmic auxiliary (MPA) proteins involved in synthesis of HMW CPS and EPS $[45,88]$. The deletion of entire $p s s P$ gene led to a non- mucoid non-nitrogen fixing mutant [89]. PssN protein turned out to be similar to outer membrane auxiliary (OMA) proteins [90]. pssL encodes a protein which shares secondary structure similarity with Wzx-type flippases acting in specific $\mathrm{O}$-antigen translocation from the inner to outer leaflet of the cytoplasmic membrane $[43,91]$. Genetic organization of the pss gene clusters of R. leguminosarum is shown in Fig. 4.

Mutants in thus far identified pss genes of R. leguminosarum bv. trifolii could be divided into 2 groups. The first one includes mutants entirely deficient in EPS production, affected in the genes essential for EPS biosynthesis that induce almost non-invaded, empty nodules with symptoms of plant defense reactions; these include $p s s A$, $p s s D$ and $p s s P$ mutants. The other one encompasses mutants that produced altered amounts of EPS in comparison to the wild type strain and formed partially infected nodules in which bacteria occupied mainly the younger zones and bacteroids were effective or ineffective in nitrogen fixation $[92,93]$.

Several other genes important for EPS synthesis, but not necessarily directly involved in, were also recognized. The prsDE genes encode two components of a type I protein secretion system that is required for the secretion of the nodulation protein NodO and extracellular proteins with polysaccharide degradation activity in R. leguminosarum bv. viciae [71] [Fig. 4]. NodO is a $\mathrm{Ca}^{2+}$-binding protein that was proposed to form channels in plant plasma membrane and has a role in signaling during legume nodulation [94]. prsD mutant of Rhizobium leguminosarum bv. viciae lacks the ability to degrade EPS in a plate assay [71]. prs $D$ mutants in both biovars produced EPS with an increased degree of polymerization and elicited more nodules that were fully infected with bacteroids unable to fix nitrogen $[71,95]$.

In $R$. leguminosarum bv. viciae plyA and plyB genes encode glycanases. plyA mutation did not affect EPS processing, while $p l y B$ mutant was characterized by a significant increase in culture viscosity [Fig. 4]. The number of nodules induced on peas by $p l y A$ and $p l y B$ mutants was normal and this correlated with normal levels of nitrogen fixation, what showed that neither of these genes is required for establishment of nitrogen-fixing symbiosis [96]. It was shown that PlyA is a surface-attached enzyme, while PlyB diffuses away from the cells. Both these extracellular glycanases are inactive unless in contact with the cell surface. It was proposed that a component associated with EPS biosynthesis or other cell surface-related component induces this activation [97]. 


\section{Regulation of exopolysaccharide synthesis}

Biosynthesis of exopolysaccharides in Rhizobium is a very complex process regulated at both transcriptional and posttranslational levels and influenced by various environmental conditions. Extensive genetic studies resulted in the identification of several regulators of EPS I and EPS II synthesis in $S$. meliloti. The exoR, exoS, mucR, expR, syrM and $e x o D$ genes are mapped on the chromosome and $\operatorname{exo} X$, exs $B$ and $\exp G$ genes on the second megaplasmid, pSymB [5].

\section{Regulation of succinoglycan biosynthesis}

\section{exoR and exoS genes}

Two chromosomal regulatory genes exoR and exoS regulate negatively succinoglycan synthesis. exoR and exoS mutants overproduce succinoglycan [51]. The expression level of exoA-, exoF-, exoP-, exoY- and exoQ-phoA translational fusions was much higher in the exoR and exoS background, indicating that both these genes affect the expression of other exo genes [51,98]. ExoS is a membrane-bound sensor histidine kinase that acts together with the response regulator ChvI, forming the ExoS-ChvI two-component regulatory system of EPS I synthesis [61]. According to the hypothetical model of the regulation of EPS I synthesis by the ExoS-ChvI system, ExoS forms homodimers in the inner membrane, and the periplasmically located sensor domain of ExoS switches between activated and nonactivated forms. In the presence of unknown environmental signal, the sensor domain is activated, passes the signal through the membrane and activates the cytoplasmic kinase. The response regulator, ChvI is then phosphorylated and activates transcription of exo genes, thereby increasing production of succinoglucan [61]. Interestingly, exoS mutants induce nitrogen-fixing nodules on alfalfa roots while exoR mutant does not [51] [Fig. 5].

EPS I synthesis is greatly enhanced by ammonia starvation via a regulatory system encoded by exoR and exoS [50]. ExoR seems to be involved directly in the response to nitrogen, because EPS I synthesis in exoR mutants does not depend on the presence of ammonia in the medium.

Recently, it was found that ExoR and the ExoS/ChvI regulatory system are not only involved in the regulation of EPS I, but also in the flagellum biosynthesis [99]. Both exoR and exoS mutations suppressed the expression of all $S$. meliloti flagellum biosynthesis genes and consequently the cells lost the ability to swarm and swim [99]. These findings suggested that flagellum biosynthesis and succinoglycan production might be coordinated at the level of gene expression. It was shown in microarray analysis that exoR mutation causes downregulation of 160 genes and upregulation of 131 genes, indicating that exoR may be involved in several metabolic pathways [99].

\section{exs $B$ gene}

This gene negatively regulates EPS I biosynthesis and is located on pSymB megaplasmid in $24 \mathrm{~kb}$ exo region [57]. exs $B$ mutants produce a three-fold increased amount of EPS I in comparison to the wild-type strain. High copy number of exsB results in a decrease in EPS I level to $20 \%$ of the wild type. This is not due to the transcriptional regulation of exo genes by the ExsB, because no significant influence of the exs $B$ mutation on the expression of exo$l a c Z$ and exs-lac $Z$ transcriptional fusions was detected. The only exception is the reduction of the exoK-lacZ activity in the exs $B$ background. exoK encodes for a glycanase which contributes to the production of low-molecular-weight EPS I. A decrease in the exoK-lacZ expression was also observed in the mucR background [19]. These data indicate that negative influence of ExsB on EPS I synthesis occurs posttranscriptionally or posttranslationally $[5,48]$.

\section{exoX gene}

It is mapped on the pSymB megaplasmid and negatively regulates EPS I biosynthesis. ExoX, a small, inner membrane-attached protein, was originally characterized in $R$. leguminosarum bv. phaseoli as PsiA [100], Rhizobium sp. NGR234 [101] and then in S. meliloti [52,65]. In the exoX mutant a 3 -fold overproduction of EPS I is observed, whereas inhibition of EPS I production occurs when exoX gene is present in the cells in higher copy number than exoY, encoding first IP-galactosyltransferase. This regulation occurs posttranslationally, since exo genes expression is unaffected in exoX background. Both ExoX and ExoY proteins are attached to the inner membrane and there is suggestion that ExoX may inhibit EPS I synthesis by interacting with ExoY [59].

\section{syrM gene}

In $S$. meliloti this gene encodes a regulatory protein that influences both Nod factor synthesis and EPS I production [102]. SyrM shows similarity to NodD proteins and together with NodD belongs to the LysR family of transcriptional activators [102]. SyrM activates transcription of nodD3 and syrA genes. It was established that genes involved in nitrogen regulatory processes $(n t r C)$ or nitrogen control of Nod factor synthesis ( $y r m$ ) are also required for EPS I production [103]. Under nitrogen limitation both NtrC and SyrM act as positive regulators of EPS I production. Mutations in these two genes decrease EPS I production under nitrogen starvation. Further experiments confirmed that syrM affects the expression of exo genes (exoF and exoP) via positive stimulation of syrA and negative influence on exoK gene [102]. SyrM is also involved in the determination of the EPS I LMW to HMW ratio and its effect depends on both nitrogen availability and the presence of the plant flavonoid luteolin [103] [Fig. 5]. 


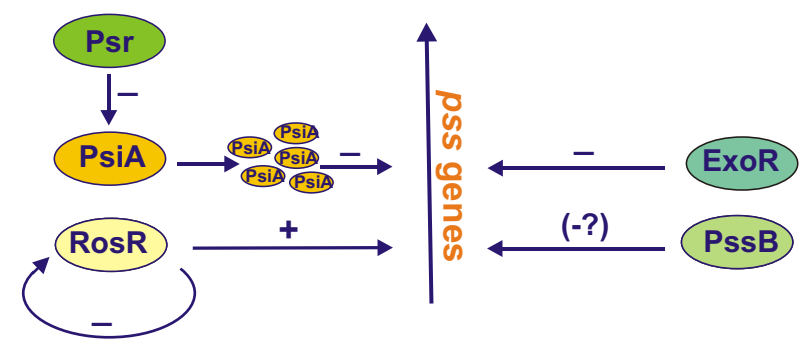

Figure 6

Model of the regulation of EPS production in $R$. leguminosarum based on $[79,81,100,114,116,119,123]$.

\section{exoD gene}

Its role in EPS I biosynthesis is yet unknown. exoD mutants produce a reduced amount of EPS I indicating positive regulation by exoD gene. Furthermore, the exoD mutants are sensitive to alkaline conditions, and effective nodulation of alfalfa by these mutants can only occur in slightly acidic plant growth media [52].

\section{Regulation of galactoglucan biosynthesis}

Under standard growth conditions, S. meliloti cells produce large amounts of EPS I and almost no EPS II. Under phosphate-limiting conditions the wild-type strains produce alternative exopolysaccharide, EPS II [17]. The production of EPS II is also observed in the presence of a mutation in either of the regulatory genes $\operatorname{expR}[20]$ or mucR $[18,19,70]$.

\section{$\exp R$ and mucR genes}

Both genes negatively regulate biosynthesis of galactoglucan. The $\operatorname{expR}$ mutant synthesizes symbiotically active high and low-molecular-weight EPS II, whereas mucR mutant and wild type strain growing under phosphate limitation produce only symbiotically inactive, high molecular weight EPS II $[22,104]$. ExpR protein is a member of LuxR family of proteins, many of which are receptors for $\mathrm{N}$-acylhomoserine lactones (AHLs) and belong to transcriptional regulators involved in a quorum-sensingdependent gene expression. S. meliloti ExpR activates transcription of exp genes in a density-dependent fashion $[21,105]$. The synthesis of symbiotically active EPS II is regulated by the Sin quorum-sensing system in the presence of ExpR protein $[105,106]$. The Sin system composed of SinR (transcriptional regulator) and SinI (autoinducer synthase) is responsible for the synthesis of long-chain $\mathrm{N}$ acyl homoserine lactones - AHLs. At least one of these AHLs $\left(\mathrm{C}_{16: 1}-\mathrm{HL}\right)$ specifically activates the expression of the exp genes and subsequent production of EPS II. The disruption of sinI resulting in the absence of AHLs causes a decrease in EPS II production and in the number of nodules per plant, indicating a role for quorum sensing in symbiosis $[105,106]$. Under these circumstances, EPS II synthesis is abolished, but EPS I is still present, indicating that $\sin R I$ system controls only production of EPS II. The exp genes are strongly induced in the presence of the sin-

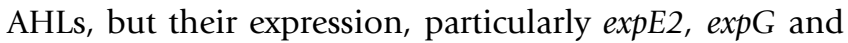
$\operatorname{expC}$, is also dependent on an active ExpR regulator: both $\exp R^{-}$mutant and $\exp R^{+} \sin I^{-}$mutants are unable to produce EPS II $[105,106]$.

In $S$. meliloti, the regulatory protein MucR plays a key role in controlling the biosynthesis of EPS I and EPS II [19]. Mutations in $m u c R$ result in high-level synthesis of EPS II, while only very small amounts of LMW EPS I are produced $[17,22,107]$. MucR is highly similar to Ros protein, a negative regulator of vir genes and necessary for succinoglycan production in Agrobacterium tumefaciens. Similarly to Ros, MucR contains a putative zinc-finger motif of the $\mathrm{C}_{2} \mathrm{H}_{2}$ type and negatively regulates not only the exp transcription but also its own transcription, by binding to a short DNA region located upstream of the $m u c R$ gene $[19,108]$. In contrast to strong repression of exp genes, only a weak stimulatory effect of MucR on the transcription of some exo genes was observed. In the presence of mucR mutation, the expression of exoH-lacZ and exoX-lacZ was slightly increased, but the expression of an exoY-lacZ fusion was 1.5-fold lower in comparison to wild-type background. MucR regulates EPS I production by binding to an inverted repeat motif (Ros-box) located upstream of exoH, exoX and exoY genes influencing the levels of their expression $[107,108]$.

EPS II can substitute for succinoglycan in bacterial invasion of root nodules. The symbiotic defects of exo mutants can be suppressed in the presence of $\operatorname{expR}$ mutation [20], which derepresses synthesis of EPS II. Medicago sativa plants inoculated with expR exo mutants producing only EPS II form nitrogen-fixing nodules [20]. On the other hand, mucR exo mutants are not invasion proficient. While both strains produce HMW EPS II, only $\operatorname{expR}$ strains produce LMW EPS II. $m u c R$ strains fail to produce LMW EPS II and are unable to invade $M$. sativa $[19,20]$.

\section{expG gene}

The expG gene (previously described as mucS by Astete and Leigh [109] located on pSymB megaplasmid, positively regulates EPS II synthesis [70]. So far, ExpG in the EPS II synthesis and MucR in the EPS I synthesis are the only two proteins that positively influence EPS synthesis in $S$. meliloti. ExpG belongs to the MarR family of transcriptional activators that bind through a helix-turn-helix motif to promoter regions in the galactoglucan biosynthesis exp gene cluster [110-112]. Extra copies of expG and phosphate limitation stimulate the transcription of all exp genes. Increase in the transcription is lower in the mutant

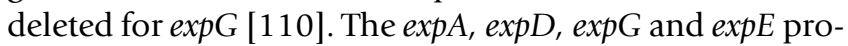


moters contain sequences similar to PhoB-binding site (PHO box) found in phosphate-regulated promoters in $E$. coli. In S. meliloti, phoB gene is required for the expression of exp genes under phosphate starvation $[110,112]$. It was established, by means of single-molecule force spectroscopy based on atomic force microscopy that the transcriptional regulator ExpG binds to conserved short palindromic sequences located upstream of $\exp A 1, \exp \mathrm{G} /$ $\operatorname{expD1}$ and $\operatorname{expE1}$ to activate expression of $\exp$ genes. Mutations in the palindrome led to no recognizable binding [113]. ExpG binding sites overlap with the putative PHO boxes identified in exp promoter regions [110], suggesting common regulation of exp gene expression by ExpG and PhoB proteins [113] [Fig. 5].

\section{Regulation of EPS biosynthesis in Rhizobium leguminosarum}

Regulatory mechanisms and environmental factors that influence EPS production in $R$. leguminosarum have not been extensively studied. Up to now, only few regulatory genes have been identified.

\section{psiA - psr genes}

On the R. leguminosarum bv. phaseoli Sym plasmid, two regulatory genes, $p s i$ (polysaccharide inhibition) and $p s r$ (polysaccharide restoration), were identified near nod-nif region [100,114-116]. The psiA mutant is not altered in its ability to produce EPS, however, it elicits empty nodules without infections threads and bacteria on Phaseolus $[100,114]$. Extra copies of $p s i A$ prevent production of EPS in R. leguminosarum bv. phaseoli and bv. viciae and abolish nodulation ability of their respective hosts. The inhibitory effect of multiple copies of psiA on nodulation and EPS production might be overcome in the presence of additional copies of the $p s r$ [100] or pssA encoding the first glucosyl-IP-transferase $[114,116]$. It was shown that transcription of $p s i$ is repressed by psr gene product [100] [Fig. 6].

PsiA is a $10 \mathrm{kDa}$ protein with some similarity to ExoX of $S$. meliloti. Both are small, inner membrane-attached polypeptides with similar hydrophobicity profiles $[52,65,115]$. When present in multiple copies, the psiA, similarly to exoX, inhibits EPS synthesis and this effect can be overcome when pssA (likely to exoY) is also present in extra copies. It has been suggested that PsiA/ExoX functions as a posttranslational inhibitor of PssA/ExoY $[64,81,101]$. In one of the proposed models, the PsiA/ ExoX and PssA/ExoY proteins form a regulatory complex; when sufficient PsiA/ExoX is bound to PssA/ExoY, the biosynthetic function of the latter is inhibited. This interaction could occur as a part of the membrane-bound complex that synthesizes EPS, because both PsiA/ExoX and PssA/ExoY have hydrophobic domains indicating their possible membrane locations.
PsrA belongs to a family of transcriptional regulators containing helix-turn-helix DNA-binding motif. The R. leguminosarum bv. phaseoli psr mutant produces a normal level of EPS and induces nitrogen-fixing nodules on Phaseolus beans. Strains with extra copies of $p s r$ induce empty nodules. This effect can be interpreted as being due to the lack of expression of psiA in bacteria during infection [100]. It was proposed that the function of $p s i A$ is to inhibit EPS synthesis during nodule development. Bacteroids within nodules make little or no EPS.

\section{rosR gene}

The ros $R$ was identified on the chromosome of $R$. etli [117]. RosR from R. etli is almost identical to RosR from R. leguminosarum bv. trifolii (99,7\% identity) [118] and highly similar to the MucR from S. meliloti and Ros of A. tumefaciens. Both Ros and MucR act as transcriptional repressors of vir and exp genes, respectively, by binding to the promoter regions of regulated genes via zinc finger motifs [19]. The RosR from R. etli plays a critical role in both nodulation competitiveness and modification of surface polysaccharides [117]. The ros $R$ mutant forms domed colonies that result from hydrophobic cell surface. It nodulates and fixes nitrogen, but when the mutant and the wild type strains are coinoculated in equal amounts, nearly all of the root nodules are occupied by the parent strain, indicating drastically reduced nodulation competitiveness of the rosR mutant [117]. A genome-wide genetic screening of the $R$. etli RosR regulon has revealed that RosR affects expression of many functionally diverse genes, usually acting as transcriptional repressor [119]. RosR negatively regulated genes with similarity to exoB, exoY, exs $H$, prsD, pss $K$ and $p l y A$, which are involved in different steps of exopolysaccharide biosynthesis. Sequences almost identical to the Ros-box were also identified upstream the pssB and pss $A$ genes in R. leguminosarum bv. trifolii $[120]$ indicating the possibility of regulation by the ros $R$ protein product.

\section{exoR gene}

The exoR was identified on the chromosome of $R$. leguminosarum bv. viciae [121]. Extensive sequence similarity between ExoR of R. leguminosarum bv. viciae and ExoR of S. meliloti, and likeness of their hydrophobicity profiles suggest possible functional resemblance of both proteins. $R$. leguminosarum bv. viciae exoR mutant produces threefold increased amounts of EPS in comparison to the wildtype strain, what indicates a negative regulation of EPS synthesis by this gene. Inoculation of pea with exoR mutant resulted in the formation of mostly red with minority of white nodules. This contrasts with the behavior of exoR mutant of S. meliloti [50]. 


\section{pssB gene}

Upstream $p s s A$, the $p s s B$ was identified in R. leguminosarum bv. viciae [79] and bv. trifolii [122]. The pssB non-polar mutant synthesizes increased amount of EPS and induces nodules with bacteroids that do not fix nitrogen. Extra copies of $p s s B$ in the wild-type strain reduce the level of EPS production [123]. This indicates that $p s s B$ could play a role in negative regulation of EPS synthesis in R. leguminosarum bv. trifolii. The pssB encodes a protein homologous to members of a family of inositol monophosphateses (IMPases) present in diverse prokaryotic and eukaryotic organisms [124]. Biochemical function of PssB in R. leguminosarum bv. trifolii as inositol monophosphatase was confirmed experimentally [125]. Mammalian IMPases are responsible for conversion of inositol monophosphates to free inositol that is necessary for regeneration of inositol-containing phospholipids. The role of IMPase in Rhizobium metabolism is unclear. The PssB protein may generate the inositol pool that is abundant in both pea and soybean nodules and is compound commonly found inside bacteroids of R. leguminosarum bv. viciae and Bradyrhizobium japonicum. Another possibility is that myo-inositol catabolism may be important for survival and competition of Rhizobium in the rhizosphere [123] [Fig. 6].

Exopolysaccharide synthesis in rhizobia is regulated both in the free-living stage and during symbiosis. In the freeliving stage, limiting nitrogen or phosphate stimulate EPS synthesis via several regulatory genes and circuits [5]. In $R$. leguminosarum bv. trifolii stimulating effect of phosphate and ammonia on acidic EPS production was described. Under phosphate sufficient conditions expression of pss $A$ increased 15-fold and pss $B$, pss $O$ genes 2-3-fold, respectively $[124,125]$. In the presence of ammonia, expression of $p s s A$ and $p s s B$ genes was repressed, but EPS production was enhanced. Clover root exudate positively influenced expression of both genes, indicated a possibility of flavonoid dependent manner of EPS biosynthesis in R. leguminosarum bv. trifolii [125].

The pssA-gusA fusion was not expressed in clover and vetch nodules [114,124]. Since PssA is the first enzyme acting in the biosynthesis of octasaccharide subunit, most probably, the EPS is not synthesized inside the nodules. On the other hand, the $p s s B, p s s O$ and $p s s P$ genes were expressed during symbiosis although the expression was restricted to younger developmental zones of nodules [124,125].

In the case of $S$. meliloti exo genes, the expression of exoF was shown to occur only in the invasion zone of the nodule, but not in the older regions of the nodule. This suggests that succinoglycan production is turned off after the invasion of plant cells but before their differentiation into bacteroids [64].

\section{Biological function of exopolysaccharide in symbiosis}

Despite many experimental data, the role of EPS in symbiosis is still not well understood. However, several possible biological functions of EPS are postulated. These include a mechanistic role in protecting bacteria against environmental stresses, involvement in early steps of plant infection, such as attachment of bacteria to the roots, structural role in the infection thread formation, release of bacteria from infection threads, bacteroid development, suppression of plant defense responses and protection against plant antimicrobial compounds $[5,10]$. The most controversial among the proposed EPS functions is that assuming its role as a signaling molecule triggering plant developmental response and a determinant of host-specificity [13].

\section{Is EPS essential for bacterial attachment to root hairs?}

Dazzo et al. [126] distinguished two steps in the attachment process. Primary attachment could be established by recognition of root-hair lectins by the specific surface carbohydrates of rhizobia. EPS may enhance the attachment of bacteria to the tip of growing root hairs and is essential for infection of emerging epidermal root hairs. However, exopolysaccharide-deficient mutants are not significantly impaired in attachment to the roots of clover [83], vetch [11] or alfalfa [61]. The surface proteins called rhicadhesins could also play a role in the primary attachment [127]. During the next stage, the firm attachment of bacteria, their removal from the roots is difficult. Involvement of cellulose fibrils was postulated in this process [127-129]. Cellulose-deficient mutants of $R$. leguminosarum bv. viciae do not form cap-like aggregates on root hair tips and only single bacteria attach to root hair surface. These strains normally nodulate Vicia plants, in contrast to EPS-deficient mutants that do not invade the nodules [127-129]. Interestingly, EPS- and cellulose-deficient double mutants formed infection threads partially occupied by bacteria [129]. According to the authors, deficiency in cellulose decreased the agglutination of Exo- strains and the infection could proceed. EPS-deficiency causes increased bacterial agglutination that inhibits infection threads elongation and colonization of nodule primordium $[61,129,130]$. Thus, the proposed function of wild-type strain EPS is involvement in the infection thread elongation by masking cellulose fibrils, the prevention of bacterial autoagglutination and stimulation of infection threads colonization.

\section{Is EPS a determinant of host-plant specificity in nodulation?}

Several experimental data evidenced that EPS production by rhizobia that nodulate host legumes forming indeterminate-type nodules, such as Vicia, Medicago, Pisum or Trifolium, is required for tight root hair curling, proper infection thread formation, bacteria release, bacteroid 
development and the effective nodulation $[11,83,93,130,131]$. Two types of experiments aimed at uncovering the specific role of EPS in symbiosis. Firstly, root hair curling and infection thread formation could be restored in EPS deficient mutants by addition of small amounts of a specific low molecular weight fraction of EPS $[22,35,101,130,131,133]$. Secondly, coinoculation of the Exo- mutants with a Nod-Exo ${ }^{+}$isogenic strain restored the process of nodule invasion $[34,35,132,133]$.

S. meliloti exo mutants unable to invade the nodule tissue, in the presence of specific low molecular weight fractions of EPS I, EPS II and KPS formed nodules that were invaded by nitrogen-fixing bacteroids $[22,24,132,133]$. The symbiotic deficiencies of exo mutants could be restored by the addition of picomolar quantities of trimer fraction of the EPS I $[24,132]$ or EPS II fraction containing 15-20 units. These data strongly suggest that low molecular weight EPS may act as a signaling molecule during invasion process in $S$. meliloti symbiosis [22]. In the case of R. leguminosarum bv. trifolii purified EPS fractions restored the nodulation of exo mutants [35]. Because EPS from non-homologous strains or structurally changed homologous EPS could not compensate for symbiotic deficiency, it was concluded that EPS structure could be one of determinants (but not major) of the host specificity at early stages of root infection. In the case of S. meliloti EPS I, EPS II and KPS structures are quite different and even though they complement symbiotic deficiencies of each other it would be surprising that their structure could be the basis for host specificity.

Nodulation deficiency of exo mutants of Rhizobium sp. NGR234, S. meliloti, or R. leguminosarum could also be repaired by coinoculation with isogenic (or similar) nonnodulating but EPS producing rhizobia $[12,35,101,134,135]$. These data pointed at structural requirements for rhizobial EPS in a successful symbiosis. Recently, this hypothesis was again tested by coinoculation of Vicia sativa roots with $R$. leguminosarum bv. viciae pssD mutant and a number of EPS producing, heterologous rhizobia ( $R$. tropici, A. tumefaciens, S. meliloti) [13]. Fix nodules were formed only on roots infected with rhizobia producing identical ( $R$. leguminosarum bv. viciae and bv. trifolii) or similar EPS (R. leguminosarum and $R$. tropici). These observations supported the hypothesis that host-specific infection is dependent on EPS structure [13]. However, the same heterologous strains were able to infection thread and nodule formation on Vicia sativa after the acquisition of the pSym plasmid of R. leguminosarum bv. viciae $[13,34]$. This indicates that infection of root tissue by rhizobia can occur regardless of EPS structure and that the Nod factor is the only determinant of the host specificity. Moreover, studies by van Rhijn et al. [136] showed that $R$. leguminosarum bv. viciae producing $S$. meliloti Nod factor could successfully infect alfalfa transgenic for pea lectin despite the different EPS structure. At present, these results do not allow to finally explain obvious controversies between the two types of experiments concerning EPS specificity in symbiosis.

\section{Role of exopolysaccharide in the evasion of plant defense response}

Plants have evolved several defense mechanisms against bacterial infection, such as: antimicrobial compounds, phytoalexins and reactive oxygen species $[137,138]$. On the other hand, there are several ways that plant pathogenic and symbiotic bacteria use to avoid plant defense system and to protect themselves [138]. Numerous evidences indicate that rhizobial surface polysaccharides such as EPS, CPS, LPS, and glucan play important roles in protection against the host defense [138]. However, mutations changing surface polysaccharides are usually pleiotropic $[8,10,93,124]$ and influence different metabolic pathways, so the function of particular polysaccharide in the induction or suppression of plant defense is difficult to evaluate. Biological role of LPS and KPS in symbiosis was recently reviewed by Fraysse et al. [10] and Becker et al. [9]. Here, we focused on a role of EPS in suppression of host defense response.

It was previously hypothesized that structurally correct exopolysaccharides are required for suppression of host defense responses [130]. Changes in the structure of particular surface polysaccharides generally result in an increased sensitivity to host antimicrobial compounds.

S. meliloti mutants disabled in EPS I production elicited noninfected pseudonodules and induced plant defense response on Medicago sativa [140]. Histochemical changes in cell walls of pseudonodules cortex were observed. Cortical cells of pseudonodules were abnormally thick and incrusted with autofluorescent phenolic compounds. Cell walls and wall apposition contained callose. Phenolic compounds were more abundant in pseudonodules than in wild-type nodules [139]. Addition of low-molecular weight EPS I enabled S. meliloti mutant to infect the host plant, acting as a suppressor of defense system $[132,133]$. Moreover, LMW EPS I added to alfalfa cell cultures (but not to non-host cell cultures) could suppress the alkalinization induced by yeast elicitor, while heterologous EPS or HMW EPS I couldn't reduce the response [140]. These data indicated that in the case of $S$. meliloti $-M$. sativa symbiosis LMW EPS I could be a specific suppressor recognized by a plant defense system [140].

In R. leguminosarum bv. trifolii - Trifolium symbiosis, rhizobia totally deficient in EPS synthesis induced empty nodules with deposition of polyphenolic material, necrosis of plant cells and thick outermost cell layer, indicating plant 
defense reactions upon the infection $[11,83,89,93]$. In the case of exo mutants that produced small amounts of EPS, plant defense reactions were not so robust and release of bacteria from infection threads could be observed; however, bacteroids were not fully developed and were not able to fix nitrogen $[83,92,93,131]$. This indicated that EPS might act by masking important bacterial antigens at the stage of nodule cells infection.

In Bradyrhizobium japonicum - Glycine max symbiosis, the exoB mutant producing structurally changed EPS induced nodules, in which significant amounts of phytoalexin glyceollin accumulated [141]. This antimicrobial compound normally accumulates during infection of soybean by pathogenic Phytophthora megasperme [142]. In Azorhizobium caulinodans - Sesbania rostrata symbiosis, mutants deficient in EPS production were blocked at an early stage of invasion. According to the authors [143], EPS produced during this early stage is required as a diffusion barrier protecting bacteria against toxic $\mathrm{H}_{2} \mathrm{O}_{2}$ generated by the host. The establishment of functional symbiosis probably depends on several mechanisms responsible for plant defense suppression and understanding of these mechanisms will be a goal of the future studies.

\section{Conclusion}

Extracellular polysaccharides (EPS) are species-specific complex carbohydrate polymers exported outside the bacterial cell. They have been a subject of a great interest for a long time because of their importance in successful development of symbiosis with legume hosts. A great progress in rhizobial genomes sequencing allows recognizing hitherto unknown genetic regions, putatively involved in the synthesis of surface polysaccharides. Functional analyses of these regions may result in recognition of specific metabolic and regulatory circuits. On the other hand, development of molecular approaches advanced our understanding of the biosynthesis, expression and regulation of exopolysaccharides, especially in Sinorhizobium meliloti. The knowledge of these processes in Rhizobium leguminosarum still remains insufficient. Recently, important new achievements on quorum-sensing and phosphate dependent regulation of EPS synthesis in S. meliloti have been made, by means of global transcriptome analyses. The important goal for the future research should be the elucidation of mechanisms of EPSs action as signaling molecules in the initiation and development of symbioses and mechanisms underlying the control of plant defense systems, which enable rhizobia to invade legume plants.

\section{Competing interests}

The author(s) declare that they have no competing interests.

\section{Authors' contributions}

All the authors were equally engaged in preparing the manuscript. AS co-directed and supervised the work.

\section{Acknowledgements}

The Polish Committee for Scientific Research grant No 2 P04A 03426 supported this work.

\section{References}

I. Broughton W], Jabbouri S, Perret X: Keys to symbiotic harmony. J Bacteriol 2000, I82:564I-5652.

2. Schulze M, Kondorosi E, Ratet P, Buire M, Kondorosi A: Cell and molecular biology of Rhizobium-plant interaction. Int Rev Cytol 1998, I 56: I-75.

3. Spaink HP: Root nodulation and infection factors produced by rhizobial bacteria. Ann Rev Microbiol 2000, 54:257-288.

4. Long SR: Genes and signals in the Rhizobium -legume symbiosis. Plant Physiol 200I, I 25:69-72.

5. Becker A, Pühler A: Production of exopolysaccharides. In Rhizobiaceae Edited by: Spaink HP, Kondorosi A, Hooykaas PJj. Kluwer Acad Publ. Dordrecht, Boston, London; 1998:97-II8.

6. Kannenberg EL, Brewin NJ: Host-plant invasion by Rhizobium : the role of cell-surface components. Trends Microbiol 1994, 2:277-283.

7. Miller KJ, Kennedy EP, Reinhold VN: Osmotic adaptation by Gram-negative bacteria: possible role for periplasmic oligosaccharides. Science 1986, 231:48-5I.

8. Breedveld MW, Cremers HC, Batley M, Posthumus MA, Zevenhuizen LP, Wijfelman CA, Zehnder AJ: Polysaccharide synthesis in relation to nodulation behavior of Rhizobium leguminosarum. J Bacteriol 1993, I75:750-757.

9. Becker A, Fraysse N, Sharypowa L: Recent advances in studies on structure and symbiosis-related function of rhizobial K-antigens and lipopolisaccharides. Mol Plant Microbe Interact 2005, 18:899-905.

10. Fraysse N, Couderc F, Poinsot V: Surface polysaccharide involvement in establishing the rhizobium-legume symbiosis. Eur J Biochem 2003, 270:1365-1380.

II. van Workum WAT, van Slageron S, van Brussel AAN, Kijne JW: Role of exopolysaccharide of Rhizobium leguminosarum bv. viciae as host plant-specific molecules required for infection thread formation during nodulation of Vicia sativa. Mol Plant Microbe Interact 1998, II:1233-124I.

12. van Workum WAT, Kijne JW: Biosynthesis of rhizobial exopolysaccharides and their role in the root nodule symbiosis of leguminous plants. In Phytochemical Signals and Plant-Microbe Interaction Edited by: Romeo C. New York: Plenum Press; 1998: 139 - 166.

13. Laus MC, van Brussel AAN, Kijne JW: Exopolysaccharide structure is not a determinant of host specificity in nodulation of Vicia sativa roots. Mol Plant Microbe Interact 2005, 1 8: I I 23-I I 29.

14. Reinhold BB, Chan SY, Reuber TL, Marra A, Walker GC, Reinhold VN: Detailed structural characterization of succinoglycan, the major exopolysaccharide of Rhizobium meliloti Rm I 021. J Bacteriol 1994, 176:1997-2002.

15. Her GR, Glazebrook J, Walker GC, Reinhold VN: Structural studies of a novel exopolysaccharide produced by a mutant of Rhizobium meliloti strain Rm 102I. Carbohydr Res 1990, 198:305-312.

16. Zevenhuizen LPTM: Succinoglycan and galactoglucan. Carbohydr Polym 1997, 33: I39-I 44.

17. Zhan H, Lee CC, Leigh JA: Induction of second exopolysaccharide (EPSb) in Rhizobium meliloti SU47 by low phosphate concentrations. J Bacteriol 1991, 173:7391-7394.

18. Zhan HJ, Levery SB, Lee CC, Leigh JA: A second exopolysaccharide of Rhizobium meliloti strain SU47 that can function in root nodule invasion. Proc Natl Acad Sci USA 1989, 86:3055-3059.

19. Keller M, Roxlau A, Weng WM, Schmidt M, Quandt J, Niehaus K, Jording D, Arnold W, Pühler A: Molecular analysis of the Rhizobium meliloti mucR gene regulating the biosynthesis of the exopolysaccharides succinoglycan and galactoglucan. Mol Plant Microbe Interact 1995, 8:267-277.

20. Glazebrook J, Walker GC: A novel exopolysaccharide can function in place of the Calcofluor-binding exopolysaccharide in 
nodulation of alfalfa by Rhizobium meliloti. Cell 1989 , 56:66I-672.

21. Pellock BJ, Teplicki M, Boinay RP, Bauer WD, Walker WC: A LuxR homolog controls production of symbiotically active extracellular polysaccharide II by Sinorhizobium meliloti. J Bacteriol 2002, 184:5067-5076.

22. Gonzalez JE, Reuhs B, Walker GC: Low molecular weight EPS II of Rhizobium meliloti allows nodule invasion in Medicago sativa. Proc Natl Acad Sci USA 1996, 93:8636-864I.

23. Gonzalez JE, Semino CE, Wang LX, Castellano-Torres LE, Walker GC: Biosynthetic control of molecular weight in the polymerization of the octasaccharide subunits of succinoglycan, a symbiotically important exopolysaccharide of Rhizobium meliloti. Proc Natl Acad Sci USA 1998, 95: I3477-I 3482.

24. Wang L-X, Wang Y, Pellock BJ, Walker GC: Structural characterization of the symbiotically important low-molecular-weight succinoglycan of Sinorhizobium meliloti. J Bacteriol 1999, | 81:6788-6796.

25. Putnoky P, Petrovics G, Kereszt A, Grosskopf E, Ha DT, Banfalvi Z, Kondorosi A: Rhizobium meliloti lipopolysaccharide and exopolysaccharide can have the same function in the plantbacterium interaction. J Bacteriol 1990, 172:5450-5458.

26. Reuhs BL, Carlson RW, Kim JS: Rhizobium fredii and Rhizobium meliloti produce 3-deoxy-D-manno-2-octulosonic acid-containig polysaccharides that are structurally analogous to group II K antigens (capsular polysaccharides) found in Escherichia coli. J Bacteriol 1993, 175:3570-3580.

27. Reuhs BL, Geller DP, Kim JS, Fox JE, Kolli VSK, Pueppke SG: Sinorhizobium fredii and Sinorhizobium meliloti produce structurally conserved lipopolysaccharide and strain specific Kantigens. Appl Environ Microbiol 1998, 64:4930-4938.

28. Robertson BK, Aman P, Darvill AG, McNeil M, Albersheim P: Hostsymbiont interactions. $V$. The structure of acidic extracellular polysaccharides secreted by Rhizobium leguminosarum and Rhizobium trifolii. Plant Physiol 198I, 67:389-400.

29. O'Neill MA, Darvill AG, Albersheim P: The degree of esterification and points of substitution by $O$-acetyl and 0 -(3hydroxybutanoyl) groups in the acidic extracellular polysaccharides secreted by Rhizobium leguminosarum biovars viciae, trifolii, and phaseoli are not related to host range. J Biol Chem 1991, 266:9549-9555.

30. Amemura A, Harada T, Abe M, Higashi S: Structural studies of the acidic polysaccharide from Rhizobium trifolii 4 S. Carbohydr Res 1983, I15:165-174.

31. Canter-Cremers HCJ, Stevens K, Lugtengberg BJ], Wiiffelman CA, Batley M, Redmond JW, Breedveld M, Zevenhuizen LPTM: Unusual structure of the exopolysaccharide of Rhizobium leguminosarum bv. viciae strain 248. Carbohydr Res 199|, 2 I 8:185-200.

32. Philip-Hollingsworth S, Hollingsworth RI, Dazzo FB: Host-range related structural features of the acidic extracellular polysaccharides of Rhizobium trifolii and Rhizobium leguminosarum. J Biol Chem 1989, 264: | 46 I- 1466.

33. Robertsen BK, Aman P, Darvill AG, McNeil M, Albersheim P: Hostsymbiont interactions. $V$. The structure of acidic extracellular polysaccharides secreted by Rhizobium leguminosarum and Rhizobium trifolii. Plant Physiol 198I, 67:389-400.

34. Laus MC, Logman TJ, Van Brussel AA, Carlson RW, Azadi P, Gao MY, Kijne JW: Involvement of exo5 in production of surface polysaccharides in Rhizobium leguminosarum and its role in nodulation of Vicia sativa subsp. nigra. J Bacteriol 2004, 186:6617-6625.

35. Djordjevic SP, Chen H, Batley M, Redmond JW, Rolfe BG: Nitrogen fixation ability of exopolysaccharide synthesis mutants of Rhizobium sp. strain NGR234 and Rhizobium trifolii is restored by addition of homologous exopolysaccharides. J Bacteriol 1987, 169:53-60.

36. Mazur A, Król J, Marczak M, Skorupska A: Membrane topology of PssT, the transmembrane protein component of the type I exopolysaccharide transport system in Rhizobium leguminosarum bv. trifolii strain TAI. J Bacteriol 2003, 185:2503-25 II.

37. Kaneko T, Nakamura $Y$, Sato S, Asamizu E, Kato T, Sasamoto S, Watanabe A, Idesawa K, Ishikawa A, Kawashima K, Kimura T, Kishida Y, Kiyokawa C, Kohara M, Matsumoto M, Matsuno A, Mochizuki Y, Nakayama S, Nakazaki N, Shimpo S, Sugimoto M, Takeuchi C, Yamada $M$, Tabata S: Complete genome structure of the nitrogen-fix- ing symbiotic bacterium Mesorhizobium loti. DNA Res 2000 , 7:33I-338.

38. Finan TM, Weidner S, Wong K, Buhrmester J, Chain P, Vorholter FJ, Hernandez-Lucas I, Becker A, Cowie A, Gouzy J, Golding B, Pühler A: The complete sequence of the I, 683-kb pSymB megaplasmid from the $\mathbf{N}_{2}$-fixing endosymbiont Sinorhizobium meliloti. Proc Natl Acad Sci USA 200I, 98:9889-9894.

39. Glucksmann MA, Reuber TL, Walker GC: Family of glycosyl transferases needed for the synthesis of succinoglycan by Rhizobium meliloti. J Bacteriol 1993, 175:7033-7044.

40. Glucksmann MA, Reuber TL, Walker GC: Genes needed for the modification, polymerization, export, and processing of succinoglycan by Rhizobium meliloti : a model for succinoglycan biosynthesis. J Bacteriol 1993, 175:7045-7055.

4I. Reuber TL, Walker GC: The acetyl substituent of succinoglycan is not necessary for alfalfa nodule invasion by Rhizobium meliloti Rm I 021. J Bacteriol 1993, I 75:3653-3655.

42. Whitfield C, Paiment A: Biosynthesis and assembly of Group I capsular polysaccharides in Escherichia coli and related extracellular polysaccharides in other bacteria. Carbohydr Res 2003, 338:249I-2502.

43. Liu D, Cole RA, Reeves PR: An O-antigen processing function for $\mathbf{W x x}(\mathbf{R f b X})$ : a promising candidate for O-unit flippase. Bacteriol 1996, I 78:2102-2107.

44. Whitfield C: Biosynthesis of lipopolysaccharide O-antigens. Trends Microbiol 1995, 3: 178- I85.

45. Paulsen IT, Beness AM, Saier MH Jr: Computer-based analyses of the protein constituents of transport systems catalysing export of complex carbohydrates in bacteria. Microbiology 1997, 1 43:2685-2699.

46. Whitfield C, Roberts IS: Structure, assembly and regulation of expression of capsules in Escherichia coli. Mol Microbiol 1999, 31:1307-1319.

47. Charles TC, Finan TM: Analysis of a 1600-kilobase Rhizobium meliloti megaplasmid using defined deletions generated in vivo. Genetics 1991, 127:5-20.

48. Becker A, Kleickmann A, Keller M, Arnold W, Pühler A: Identification and analysis of the Rhizobium meliloti exoAMONP genes involved in exopolysaccharide biosynthesis and mapping of promoters located on the exoHKLAMONP fragment. Mol Gen Genet 1993, 241:367-379.

49. Becker A, Kleickmann A, Kuster H, Keller M, Arnold W, Pühler A Analysis of the Rhizobium meliloti genes exoU, exoV, exoW, exoT, and exol involved in exopolysaccharide biosynthesis and nodule invasion: exo $U$ and exoW probably encode glucosyltransferases. Mol Plant Microbe Interact 1993, 6:735-744.

50. Doherty D, Leigh JA, Glazebrook J, Walker GC: Rhizobium meliloti mutants that overproduce the $R$. meliloti acidic calcofluorbinding exopolysaccharide. J Bacteriol 1988, 170:4249-4256.

51. Reed JW, Glazebrook J, Walker GC: The exoR gene of Rhizobium meliloti affects RNA levels of other exo genes but lacks homology to known transcriptional regulators. J Bacteriol 1991, 173:3789-3794.

52. Reed JW, Walker GC: The exoD gene of Rhizobium meliloti encodes a novel function needed for alfalfa nodule invasion. | Bacteriol |99|, | 73:664-677.

53. Reed JW, Walker GC: Acidic conditions permit effective nodulation of alfalfa by invasion-deficient Rhizobium meliloti exoD mutants. Genes Dev 1991, 5:2274-2287.

54. Finan TM, Kunkel B, De Vos GF, Signer ER: Second symbiotic megaplasmid in Rhizobium meliloti carrying exopolysaccharide and thiamine synthesis genes. I Bacteriol 1986, I67:66-72.

55. Buendia AM, Enenkel B, Koplin R, Niehaus K, Arnold W, Pühler A: The Rhizobium meliloti exoZI exoB fragment of megaplasmid 2: ExoB functions as a UDP-glucose 4-epimerase and ExoZ shows homology to NodX of Rhizobium leguminosarum biovar viciae strain TOM. Mol Microbiol 1991, 5:1519-1530.

56. Becker A, Kleickmann A, Arnold W, Pühler A: Analysis of the Rhizobium meliloti exoH/exoK/exoL fragment: ExoK shows homology to excreted endo-beta-I, 3-I, 4-glucanases and ExoH resembles membrane proteins. Mol Gen Genet 1993, 238: $145-154$.

57. Becker A, Küster H, Niehaus K, Pühler A: Extension of the Rhizobium meliloti succinoglycan biosynthesis gene cluster: identification of the exsA gene encoding an $A B C$ transporter protein, and the exsB gene which probably codes for a regu- 
lator of succinoglycan biosynthesis. Mol Gen Genet 1995, 249:487-497.

58. Uttaro AD, Cangelosi GA, Geremia RA, Nester EW, Ugalde RA: Biochemical characterization of avirulent exo C mutants of Agrobacterium tumefaciens. J Bacteriol 1990, 172:1640-1646.

59. Müller P, Keller M, Weng WM, Quandt J, Arnold W, Pühler A: Genetic analysis of the Rhizobium meliloti exoYFQ operon: ExoY is homologous to sugar transferases and ExoQ represents a transmembrane protein. Mol Plant Microbe Interact 1993, 6:55-65.

60. Reuber TL, Walker GC: Biosynthesis of succinoglycan, a symbiotically important exopolysaccharide of Rhizobium meliloti. Cell 1993, 74:269-280.

61. Cheng H-P, Walker GC: Succinoglycan is required for initiation and elongation of infection threads during nodulation of alfalfa by Rhizobium meliloti. J Bacteriol 1998, 180:5 I83-5I91.

62. Leigh JA, Signer ER, Walker GC: Exopolysaccharide-deficient mutants of Rhizobium meliloti that form ineffective nodules. Proc Natl Acad Sci U S A 1985, 82:623I-6235.

63. Long S, Reed JW, Himawan J, Walker GC: Genetic analysis of a cluster of genes required for synthesis of the calcofluor-binding exopolysaccharide of Rhizobium meliloti. J Bacteriol 1985, I 70:4239-4248.

64. Reuber TL, Long S, Walker GC: Regulation of Rhizobium meliloti exo genes in free-living cells and in planta examined by using TnphoA fusions. J Bacteriol I99I, 173:426-434.

65. Zhan H, Leigh JA: Two genes that regulate exopolysaccharide production in Rhizobium meliloti. J Bacteriol 1990 , I 72:5254-5259.

66. Leigh JA, Reed JW, Hanks JF, Hirsch AM, Walker GC: Rhizobium meliloti mutants that fail to succinylate their calcofluor-binding exopolysaccharide are defective in nodule invasion. Cell 1987, 5 I:579-587.

67. Niemeyer $D$, Becker A: The molecular weight distribution of succinoglycan produced by Sinorhizobium meliloti is influenced by specific tyrosine phosphorylation and ATPase activity of the cytoplasmic domain of the ExoP protein. J Bacteriol 200I, 183:5163-5170.

68. York GM, Walker GC: The Rhizobium meliloti exoK gene and prsD/prsE/exsH genes are components of independent degradative pathways which contribute to production of lowmolecular-weight succinoglycan. Mol Microbiol 1997, 25: II7-134.

69. York GM, Walker GC: The succinyl and acetyl modifications of succinoglycan influence susceptibility of succinoglycan to cleavage by the Rhizobium meliloti glycanases ExoK and ExsH. J Bacteriol 1998, 180:4|84-4|9|.

70. Becker A, Rüberg S, Kuster H, Roxlau AA, Keller M, Ivashina T, Cheng HP, Walker GC, Pühler A: The 32-kilobase exp gene cluster of Rhizobium meliloti directing the biosynthesis of galactoglucan: genetic organization and properties of the encoded gene products. J Bacteriol 1997, I79: I375-I384.

7I. Finnie C, Hartley NM, Findlay KC, Downie JA: The Rhizobium leguminosarum prsDE genes are required for secretion of several proteins, some of which influence nodulation, symbiotic nitrogen fixation and exopolysaccharide modification. Mol Microbiol 1997, 25:135-146.

72. Moreira LM, Becker JD, Pühler A, Becker A: The Sinorhizobium meliloti ExpEI protein secreted by a type I secretion system involving ExpDI and ExpD2 is required for biosynthesis or secretion of the exopolysaccharide galactoglucan. Microbiology 2000, I 46:2237-2248.

73. Mercado-Blanco J, Toro N: Plasmids in rhizobia: the role of nonsymbiotic plasmids. Mol Plant Microbe Interact 1996, 9:535-545.

74. Jumas-Bilak E, Michaux-Charachon S, Bourg G, Ramuz M, AllardetServent A: Unconventional genomic organization in the alpha subgroup of the Proteobacteria. J Bacteriol 1998, 1 80:2749-2755.

75. Sanger Institute Sequencing Projects-Rhizobium leguminosarum biovar viciae [http://www.sanger.ac.uk/Projects/ $R$ leguminosarum/]

76. Król J, Mazur A, Marczak M, Skorupska A: Mapping of the Rhizobium leguminosarum bv. trifolii TAI genome. In Abstarct book of The First Baltic Region Symposium and postgraduate course: Agro-biotechnology focused on root-microbe systems: 20-27 May 2005; Kounas, Lithuania Edited by: Kuusiene S. Kaunas; 2005:33-34.
77. Sanchez-Andujar B, Coronado C, Philip-Hollingsworth S, Dazzo FB, Palomares AJ: Structure and role in symbiosis of the exoB gene of Rhizobium leguminosarum bv trifolii. Mol Gen Genet 1997, 255: $|3|-\mid 40$.

78. Kereszt A, Kiss E, Rheus BL, Carlson RW, Kondorosi A, Putnoky P: Novel rkp gene clusters of Sinorhizobium meliloti involved in capsular polysaccharide production and invasion of the symbiotic nodule: the rkpK gene encodes a UDP-glucose dehydrogenase. J Bacteriol 1998, I80:5426-5431.

79. Ivashina TV, Khmelnitsky MI, Shlyapnikov MG, Kanapin AA, Ksenzenko VN: The pss4 gene from Rhizobium leguminosarum bv. viciae VF39: cloning, sequence and the possible role in polysaccharide production and nodule formation. Gene 1994 , 150:111-116.

80. van Workum WAT, Canter Cremers HCJ, Wijfies AHM, van der Kolk C, Wijfelman CA, Kijne JW: Cloning and characterization of four genes of Rhizobium leguminosarum bv. trifolii involved in exopolysaccharide production and nodulation. Mol Plant Microbe Interact 1997, 10:290-301.

8I. Borthakur D, Barker RF, Latchford JW, Rossen L, Johnston AW: Analysis of pss genes of Rhizobium leguminosarum required for exopolysaccharide synthesis and nodulation of peas: their primary structure and their interaction with psi and other nodulation genes. Mol Gen Genet 1988, 21 3:155-162.

82. Janczarek M, Skorupska A: Exopolysaccharide synthesis in Rhizobium leguminosarum bv. trifolii is related to various metabolic pathways. Rhizobium 2003, I54:433-442.

83. Rolfe BG, Carlson RW, Ridge RW, Dazzo RW, Mateos FB, Pankhurst $C E$ : Defective infection and nodulation of clovers by exopolysaccharide mutants of Rhizobium leguminosarum bv. trifolii. Aust J Plant Physiol 1996, 23:285-303.

84. Sadykov MR, Ivashina TV, Kanapin AA, Shliapnikov MG, Ksenzenko VN: Structure-functional organization of exopolysaccharide biosynthetic genes in Rhizobium leguminosarum bv. viciae VF39. Mol Biol 1998, 32:797-804.

85. Król J, Wielbo J, Mazur A, Kopciñska J, \&\#×0|4I;otocka B, Golinowski W, Skorupska A: Molecular characterization of pssCDE genes of Rhizobium leguminosarum bv. trifolii strain TAI: pss $D$ mutant is affected in exopolysaccharide synthesis and endocytosis of bacteria. Mol Plant Microbe Interact 1998, I I:I I 42-I I 48.

86. Pollock TJ, van Workum WAT, Thorne L, Mikolajczak MJ, Yamazak $\mathrm{M}$, Kijne JW, Armentrout RW: Assignment of biochemical functions to glycosyl transferase genes which are essential for biosynthesis of exopolysaccharides in Sphingomonas strain S88 and Rhizobium leguminosarum. J Bacteriol 1998, I 80:586-593.

87. Guerreiro N, Ksenzenko VN, Djordjevic MA, Ivashina TV, Rolfe BG: Elevated levels of over 20 proteins results after mutation of the Rhizobium leguminosarum exopolysaccharide synthesis gene pssA. J Bacteriol 2000, 182:452 I-4532.

88. Becker A, Niehaus $K$, Pühler A: Low-molecular-weight succinoglycan is predominantly produced by Rhizobium meliloti strains carrying a mutated ExoP protein characterized by a periplasmic $\mathbf{N}$-terminal domain and a missing $\mathrm{C}$-terminal domain. Mol Microbiol 1995, 16:191-203.

89. Mazur A, Krol JE, Wielbo J, Urbanik-Sypniewska T, Skorupska A Rhizobium leguminosarum bv. trifolii PssP protein is required for exopolysaccharide biosynthesis and polymerization. Mol Plant Microbe Interact 2002, I 5:388-397.

90. Mazur A, Krol JE, Skorupska A: Isolation and sequencing of Rhizobium leguminosarum bv. trifolii pss $N$, pss $O$ and pss $P$ genes encoding the proteins involved in polymerization and translocation of exopolysaccharide. DNA Seq 200I, I2:I-I2.

91. Mazur A, Marczak M, Król JE, Skorupska A: Topological and transcriptional analysis of pss $L$ gene product: a putative $W z x$-like exopolysaccharide translocase in Rhizobium leguminosarum bv. trifolii TAI. Arch Microbiol 2005, I84:I-I0.

92. Wielbo J, Mazur A, Krol J, Marczak M, Kutkowska J, Skorupska A: Complexity of phenotypes and symbiotic behaviour of Rhizobium leguminosarum biovar trifolii exopolysaccharide mutants. Arch Microbiol 2004, I 82:33I-336.

93. Skorupska A, Białek U, Urbanik-Sypniewska T, van Lammeren A: Two types of nodules induced on Trifolium pratense by mutants of Rhizobium leguminosarum bv. trifolii deficient in exopolysaccharide production. J Plant Physiol 1995, 147:93-100. 
94. Sutton M, Lea EJ, Downie JA: The nodulation signaling protein NodO from Rhizobium leguminosarum bv. viciae forms ion channels in membranes. Proc Natl Acad Sci USA 1994, 91:9990-9994

95. Król J, Skorupska A: Identification of the genes in Rhizobium leguminosarum bv. trifolii whose products are homologues to a family of ATP-binding proteins. Microbiology 1997 143:1389-1394.

96. Finnie C, Zorreguieta A, Hartley NM, Downie JA: Characterization of Rhizobium leguminosarum exopolysaccharide glycanases that are secreted via a type I exporter and have a novel heptapeptide repeat motif. J Bacteriol 1998, 180:169|-1699.

97. Zorreguieta A, Finnie C, Downie JA: Extracellular glycanases of Rhizobium leguminosarum are activated on the cell surface by an exopolysaccharide-related component. J Bacteriol 2000, 182:1304-1312.

98. Ozga DA, Lara JC, Leigh JA: The regulation of exopolysaccharide production is important at two levels of nodule development in Rhizobium meliloti. Mol Plant-Microbe Interact 1994, 7:758-765.

99. Yao S-Y, Luo L, Har KJ, Becker A, Rüberg S, Yu G-Q, Zhu J-B, Cheng $H-P$ : Sinorhizobium meliloti ExoR and ExoS proteins regulate both succinoglycan and flagellum production. J Bacteriol 2004, I 86:6042-6049.

100. Borthakur D, Johnston AWB: Sequence of psi, a gene of the symbiotic plasmid of Rhizobium phaseoli which inhibits exopolysaccharide synthesis and nodulation and demonstration that its transcription is inhibited by psr, another gene on the symbiotic plasmid. Mol Gen Genet 1987, 207: 149-154.

I0I. Gray JX, Djordjevic MA, Rolfe BG: Two genes that regulate exopolysaccharide production in Rhizobium sp. strain NGR234: DNA sequences and resultant phenotypes. J Bacteriol 1990, I72:193-203.

102. Barnett MJ, Long SR: Identification and characterization of a gene on Rhizobium meliloti pSymA, syrB, that negatively affects syrM expression. Mol Plant-Microbe Interact 1997, 10:550-559.

103. Dusha I, Olah B, Szegletes Z, Erdei L, Kondorosi A: syrM involved in the determination of the amount and ratio of the two forms of the acidic exopolysaccharide EPSI in Rhizobium meliloti. Mol Plant-Microbe Interact 1999, I 2:755-765.

104. Mendrygal KE, Gonzalez JE: Environmental regulation of exopolysaccharide production in Sinorhizobium meliloti. J Bacteriol 2000, 182:599-606.

105. Marketon MM, Glenn SA, Eberhard A, Gonzalez JE: Quorum sensing controls exopolysaccharide production in Sinorhizobium meliloti. J Bacteriol 2003, I85:325-331.

106. Hoang HH, Becker A, Gonzalez JE: The LuxR homolog ExpR, in combination with the Sin quorum sensing system, plays a central role in Sinorhizobium meliloti gene expression. J Bacteriol 2004, I86:5460-5472.

107. Bertram-Drogatz PA, Quester I, Becker A, Pühler A: The Sinorhizobium meliloti MucR protein, which is essential for the production of high-molecular-weight succinoglycan exopolysaccharide, binds to short DNA regions upstream of exoH and exoY. Mol Gen Genet 1998, 257:433-44I.

108. Bertram-Drogatz PA, Rüberg S, Becker A: The regulatory protein MucR binds to a short DNA region located upstream of the mucR coding region in Rhizobium meliloti. Mol Gen Genet 1997 254:529-538.

109. Astete SG, Leigh JA: mucS, a gene involved in activation of galactoglucan (EPS II) synthesis gene expression in Rhizobium meliloti. Mol Plant-Microbe Interact 1996, 9:395-400.

1 10. Rüberg S, Pühler A, Becker A: Biosynthesis of the exopolysaccharide galactoglucan in Sinorhizobium meliloti is subject to a complex control by the phosphate-dependent regulator PhoB and the proteins ExpG and MucR. Microbiol 1999, |45:603-6II.

III. Bartels FW, Baumgarth B, Anselmetti D, Ros R, Becker A: Specific binding of the regulatory protein ExpG to promoter regions of the galactoglucan biosynthesis gene cluster of Sinorhizobium meliloti - a combined molecular biology and force spectroscopy investigation. J Struct Biol 2003, I43: | 45- I52.

112. Krol E, Becker A: Global transcriptional analysis of the phosphate starvation response in Sinorhizobium meliloti strains I02I and 20 I I. Mol Gen Genomics 2004, 272: I-I7.
113. Baumgarth B, Bartels FW, Anselmetti D, Becker A, Ros R: Detailed studies of the binding mechanism of the Sinorhizobium meliloti transcriptional activator ExpG to DNA. Microbiol 2005, I 5 I: I- I0.

114. Latchford JW, Borthakur D, Johnston AWB: The products of Rhizobium genes, psi and pss, which affect exopolysaccharide production, are associated with the bacterial cell surface. Mol Microbiol I99I, 5:2107-2II4.

115. Mimmack ML, Borthakur D, Jones MA, Downie JA, Johnston AWB: The psi operon of Rhizobium leguminosarum biovar phaseoli: identification of two genes whose products are located at the bacterial cell surface. Microbiol 1994, 140:1223-1229.

I 16. Mimmack ML, Hong GF, Johnston AWB: Sequence and regulation of psrA, a gene on the Sym plasmid of Rhizobium leguminosarum biovar phaseoli which inhibits transcription of the psi genes. Microbiol 1994, 140:455-46।.

117. Bittinger MA, Milner JL, Saville BJ, Handelsman J: rosR, a determinant of nodulation competitivenes in Rhizobium etli . J Bacteriol 1997, 10:180-186.

II8. Janczarek M, Skorupska A: rosR gene of Rhizobium leguminosarum bv. trifolii influencing on the exopolysaccharide production. GenBank accession no. AY683454.

119. Bittinger MA, Handelsman J: Identification of genes in the RosR regulon of Rhizobium etli. J Bacteriol 2000, 182:1706-17/3.

120. Janczarek M, Skorupska A: Mutation in the pssB-pssA intergenic region of Rhizobium leguminosarum bv. trifolii affects the surface polysaccharide synthesis and nitrogen fixation ability. J Plant Physiol 200I, I58:I565-1674.

12I. Reeve WG, Dilworth MJ, Tiwari RP, Glenn AR: Regulation of exopolysaccharide production in Rhizobium leguminosarum biovar viciae WSM7I0 involves exoR. Microbiol 1997, I 43:1951-1958.

122. Janczarek M, Król J, Skorupska A: The pssB gene product of Rhizobium leguminosarum bv. trifolii is homologous to a family of inositol monophosphatases. FEMS Microbiol Lett 1999, 173:319-325.

123. Janczarek M, Skorupska A: The Rhizobium leguminosarum bv. trifoli pss $B$ gene product is an inositol monophosphatase that influences exopolysaccharide synthesis. Arch Microbiol 200I, I75: $|43-| 5 \mid$.

124. Janczarek M, Skorupska A: Regulation of pss $A$ and pss $B$ gene expression in $R$. leguminosarum bv. trifolii in response to environmental factors. Antonie Leeuw 2004, 85:217-227.

125. Wielbo J, Mazur A, Krol JE, Marczak M, Skorupska A: Environmental modulation of the pssTNOP gene expression in $R$. leguminosarum bv. trifolii. Can J Microbiol 2004, 50: I-II.

126. Dazzo FB, Truchet GL, Sherwood JE, Hrabak EM, Abe M, Pankratz $\mathrm{SH}$ : Specific phases of root hair attachment in the Rhizobium trifolii -clover symbiosis. Appl Environ Microbiol 1984, 48: I I40-II 50.

127. Smit G, Swart S, Lugtenberg BJJ, Kijne JW: Molecular mechanisms of attachment of rhizobium bacteria to plant roots. Mol Microbiol 1992, 6:2897-2903.

128. Ausumes N, Jonsson H, Hoglund S, Ljunggren H, Lindberg M: Structural and putative regulatory genes involved in cellulose synthesis in Rhizobium leguminosarum bv. trifolii. 1999, 145: I 253-1262

129. Laus MC, van Brussel AAN, Kijne JW: Role of cellulose fibrils and exopolysaccharides of Rhizobium leguminosarum in attachment to and infection of Vicia sativa root hairs. Mol Plant Microbe Interact 2005, 18:533-538.

130. Pellock BJ, Cheng HP, Walker GC: Alfalfa root nodule invasion efficiency is dependent on Sinorhizobium meliloti polysaccharides. J Bacteriol 2000, 182:4310-4318.

I3I. Białek U, Skorupska A, Yang A, Bisseling T, Van Lammeren AAM: Disturbed gene expression and bacterial development in Trifolium pratense root nodules induced by a Tn5 mutant of Rhizobium leguminosarum bv. trifolii defective in exopolysaccharide synthesis. Planta 1995, 197: 184-192.

132. Battisti L, Lara JC, Leigh JA: Specific oligosaccharide form of the Rhizobium meliloti exopolysaccharide promotes nodule invasion in alfalfa. Proc Natl Acad Sci USA 1992, 89:5625-5629.

133. Urzainqui A, Walker GC: Exogenous suppression of the symbiotic deficiencies of Rhizobium meliloti exo mutants. J Bacteriol 1992, 174:3403-3406. 
134. Kapp D, Niehaus K, Quant J, Mûller P, Pûhler A: Cooperative action of Rhizobium meliloti nodulation and infection mutants during the process of forming mixed infected alfalfa nodules. Plant Cell 1990, 2:|39-|5I.

135. Gray JX, Zhan HJ, Levery SB, Battisti L, Rolfe BG, Leigh JA: Heterologous exopolysaccharide production in Rhizobium sp. strain NGR234 and consequences for nodule development. J Bacteriol 1991, I73:3066-3077.

136. van Rhijn P, Fujishige NA, Lim PO, Hirsch AM: Sugar-binding activity of pea lectin enhances heterologous infection of transgenic alfalfa plants by Rhizobium leguminosarum biovar viciae. Plant Physiol 200I, I 26: I 33-144.

137. Matamoros MA, Dalton DA, Ramos J, Clemente MR, Rubio MC Becana M: Biochemistry and molecular biology of antioxidants in the Rhizobia -legume symbiosis. Plant Physiol 2003, 133:499-509.

138. D'Haeze W, Holsters M: Surface polysaccharides enable bacteria to evade plant immunity. Trends in Microbiol 2004, | 2:555-56|.

139. Niehaus K, Kapp D, Pühler A: Plant defence and delayed infection of pseudonodules induced by an exopolysaccharide (EPS I)-deficient Rhizobium meliloti mutant. Planta 1993, 190:415-425.

140. Niehaus K, Baier R, Becker A, Pühler A: Symbiotic suppression of the Medicago sativa defense system -the key of Rhizobium meliloti to enter the host plant? In Biology of Plant-Microbe Interactions Edited by: Stacey G, Mullin B, Gresshoff PM. ISMPI, St. Paul; 1996:349-352.

14I. Parniske M, Schmidt PE, Kosch K, Müller P: Plant defense response of host plants with determinate nodules induced by EPS defective exoB mutants of Bradyrhizobium japonicum. Mol Plant Microbe Interact 1994, 7:63I-638.

142. Schmidt PE, Parniske M, Werner D: Production of the phytoalexin glyceollin I by soybean roots in response to symbiotic and pathogenic infection. Bot Acta 1992, 105:18-25.

143. D'Haeze W, Glushka J, De Rycke R, Holsters M, Carlson RW: Structural characterization of extracellular polysaccharides of Azorhizobium caulinodans and importance for nodule initiation on Sesbania rostrata. Mol Microbiol 2004, 52:485-500.

\section{Publish with Bio Med Central and every scientist can read your work free of charge}

"BioMed Central will be the most significant development for disseminating the results of biomedical research in our lifetime. "

Sir Paul Nurse, Cancer Research UK

Your research papers will be:

- available free of charge to the entire biomedical community

- peer reviewed and published immediately upon acceptance

- cited in PubMed and archived on PubMed Central

- yours - you keep the copyright

Submit your manuscript here:

http://www.biomedcentral.com/info/publishing_adv.asp
BioMedcentral 